\title{
SARS-CoV-2 infection reaches the human nervous system: How?
}

\author{
Vladimir N Uversky, ${ }^{1,4,5}$ Fatma Elrashdy, ${ }^{2}$ Abdullah Aljadawi ${ }^{1}$, Syed Moasfar Ali, ${ }^{3}$ \\ Rizwan Hasan Khan, ${ }^{3}$ and Elrashdy M. Redwan ${ }^{1}$
}

${ }^{1}$ Biological Science Department, Faculty of Science, King Abdulaziz University, P.O. Box 80203, Jeddah, 21589, Saudi Arabia;

${ }^{2}$ Department of Endemic Medicine and Hepatogastroenterology, Kasr Alainy School of Medicine, Cairo University, Cairo, Egypt;

${ }^{3}$ Interdisciplinary Biotechnology Unit, Aligarh Muslim University, Aligarh-202002, India;

${ }^{4}$ Department of Molecular Medicine and USF Health Byrd Alzheimer's Research Institute, Morsani College of Medicine, University of South Florida, Tampa, FL, USA.

${ }^{5}$ Institute for Biological Instrumentation of the Russian Academy of Sciences, Federal Research Center "Pushchino Scientific Center for Biological Research of the Russian Academy of Sciences”, Pushchino, Moscow region, 142290, Russia;

Corresponding authors: Uversky V.N.: vuversky@usf.edu; Redwan E.M.: lradwan@kau.edu.sa

Keywords: COVID-19; SARS-CoV-2; neurotropic virus; Blood-nervous system barrier; bloodcerebrospinal-fluid-barrier; blood-brain-barrier; blood-nerve barrier; olfactory route; Lymphatic brain drainage route; Peripheral nerve or neuronal retrograde route;

Macrophage/monocytes cargo route; Double membrane vesicles cargo route; nicotinic acetylcholine receptor 


\begin{abstract}
Without protective and/or therapeutic agents the SARS-CoV-2 infection known as coronavirus disease 2019 (COVID-19) is quickly spreading worldwide. It has surprising transmissibility potential, since it could infect all ages, gender, and human sectors. It attacks respiratory, gastrointestinal, urinary, hepatic, and endovascular systems and can reach the peripheral nervous system (PNS) and central nervous system (CNS) through known and unknown mechanisms. The reports on the neurological manifestations and complications of the SARSCoV-2 infection are increasing exponentially. Herein, we enumerate seven candidate routes, which the mature or immature SARS-CoV-2 components could use to reach the CNS and PNS, utilizing the within-body crosstalk between organs. The majority of SARS-CoV-2 infected patients suffer from some neurological manifestations (e.g., confusion, anosmia, and ageusia). It seems that although the mature virus did not reach the CNS or PNS of the majority of patients, its unassembled components and/or the accompanying immune-mediated responses may be responsible for the observed neurological symptoms. The viral particles and/or its components have been specifically documented in endothelial cells of lung, kidney, skin, and CNS. This means that the blood-endothelial-barrier may be considered as the main route for SARS-CoV-2 entry into the nervous system, with the barrier disruption being more logical than barrier permeability, as evidenced by postmortem analyses.
\end{abstract}

\title{
Introduction
}

A new, highly virulent coronavirus ( $\mathrm{CoV}$ ) capable of infecting humans (HCoV) currently holds much of the world's population hostage. This virus, referred to as SARS-COV-2 and causing the COVID-19 disease in infected subjects, emerged at the end of 2019 in China and the moment is affecting the population in at least 213 countries and territories around the world. This is only the latest in a series of lethal HcoV-caused illnesses, following the emergence of SARS-CoV in 2002 and MERS-CoV in 2012. Within the worldwide storm caused by the COVID-19 outbreak, most patients infected with SARS-CoV-2 and diagnosed with COVID19 have only mild symptoms or are entirely asymptomatic. Unfortunately, approximately $20 \%$ of infected individuals exhibit far more serious symptoms, with $15 \%$ being considered "severe" and requiring oxygen, and the remaining 5\% being viewed as "critical" and relying on ventilators. Symptoms of these serious cases include signs similar to pneumonia, septic shoock, respiratory failure, and even multi-organ failure. Thus far, an estimated 1-2\% of COVID-19 cases have proven to be fatal $[1,2]$, though it must be noted that the majority of fatalities associated with the disease happened in individuals suffering from chronic afflictions, including various cardiovascular diseases, chronic obstructive pulmonary disease (COPD), and other comorbidities [3].

Analyses of deceased SARS-CoV-2 patients have shown that the viral particles reach and are distributed in nervous system tissues (Table 1). This discovery begs several important questions: from where did SARS-CoV-2 come to the nervous system and how did it access the brain? What are the brain infection manifestations? Is viral infection persistent in the brain? Are COVID-19 deaths dependent or independent on brain infection? The goal of this work is to get some logical answers to some of these questions. 
To this end, we conducted a comprehensive analysis of existing literature, using the following search strategy and selection criteria. References for this review were collected through searches of PubMed, SCOPUS, and Web of Science for articles published until July 10, 2020. The search terms used were "coronaviruses, SARS-CoV, SARS-CoV-2, 2019-nCov, MERSCoV, 229E-CoV", and "COVID-19", combined with "nervous system", "neuroinvasion", "neurological manifestation", and "brain." In vitro studies on neurotropism potentials of CoV on neural or glial cell cultures were considered. In vivo model investigations were included for infection routes (intranasal and intraperitoneal) of neuroinvasion. Post-mortem autopsies and biopsy analyses were considered. Furthermore, clinical findings were searched and included for neurological signs related to CoVs infections.

Although the 2002-2004 outbreak of the severe acute respiratory syndrome (SARS-CoV), as well as the 2012-2020 outbreak of the middle east respiratory syndrome (MERS-CoV) and current COVID-19 are the real newsmakers, it is recognized now that in addition to SARSCoV, MERS-CoV, and SARS-CoV-2 (all are $\beta$-CoVs of the B and C lineage), there are four other coronaviruses (CoVs) capable of infecting humans (HCoVs), which circulate continuously in the human population. These are HCoV-OC43 [4,5] and HCoV-HKU1 [6] ( $\beta$ CoVs of the A lineage or $\beta 1 \mathrm{CoVs})$, and HCoV-229E [7,8] and HCoV-NL63 $[9,10](\alpha-\mathrm{CoVs})$. Identified in the late 1960s (HCoV-229E and the HCoV-OC43) [11-15] and in 2004-2005 (HCoV-NL63 [16,9,10] and HCoV-HKU1 [6]), these HCoVs are known to be responsible for $3 \%-10 \%$ cases of the common cold and short-term upper respiratory infections that occur mainly in winter, with a short incubation time $[17,18]$, with about $2 \%$ of the human population being healthy carriers of an $\mathrm{HCoV}[19,20]$. Although these $\mathrm{HCoV}$ strains can also cause more serious diseases of the lower respiratory tract, such as bronchitis, bronchiolitis, and pneumonia, especially in newborns or infants, elderly people, and immunocompromised patients [19,20], their phenotypes are generally mild, and as a result, these four HCoVs received relatively little attention. Consequently, there is abundant research into $\mathrm{CoV}$ that stems all the way back to the 1930s, which has resulted in a considerable knowledge base and various tools for further examining these pathogens in humans.

Data from the in vitro experiments on culturing SARS-CoV and SARS-CoV-2 on the cell lines derived from different human and animal organs clearly indicated that there are many similarities as well as differences between these two CoVs. One of the interesting points made in this study was that SARS-CoV-2 (but not SARS-CoV) was able to modestly replicate in the neuronal (U251) cells, which highlighted the potential of this virus to cause neurological manifestations (e.g., confusion, anosmia, and ageusia) in patients with COVID-19 [21]. The same study also showed that the pluripotent stem cell (iPSC)-derived BrainSphere model can be infected with SARS-CoV-2 (SARS-CoV-2/Wuhan-1/2020), which exponentially replicated 10 -fold there [22]. The virus particles were found in the neuronal cell body extending into apparent neurite structures. This neural cell model expressed angiotensin-converting enzyme 2 (ACE2, a SARS-CoV-2 receptor on the surface of the host cells interacting with the viral spike (S) protein) but not the transmembrane serine protease-2 (TMPRSS2, the catalytic enzyme responsible for the $\mathrm{S}$ protein priming required for the subsequent $\mathrm{CoV}$ cell entry), which suggests the presence of alternative proteolytic tools there [22]. This state-of-the-art 3D organotypic cell culture model was already successfully used in the infection studies with the Zika, Dengue, HIV, and John Cunningham (JV) viruses. The most interesting point of these studies was the fact that the functional blood-brain-barrier (BBB) had lost its functionality 
when microglia (which was not derived from the neural precursor cells but from the mesoderm germ layer) invaded the developing brain from the blood, resulting in cytokine release and neuronal damage in models analyzing the infection with HIV and JC viruses [22]. Therefore, one of the reasons why some, but not all, of the patients showed neurological manifestations could be related to the fact that the BBB normally hinders virus entry, but is impaired in some by inflammatory conditions [22].

\section{Are human coronaviruses neurotropic?}

Neurotropism of HCoVs represents an interesting problem. Data on the immune-mediated CNS pathology associated with viral infection are traditionally derived from the analysis of mice infected with a member of the Coronaviridae family, Murine Hepatitis Virus (MHV) strains, which is a $\beta$-coronavirus genetically related to Human CoV-OC4347 [23]. Being a group II coronavirus, MHV represents a natural pathogen of mice that typically infects the liver, gastrointestinal tract, and CNS, and shows various disease manifestations ranging from gastroenteritis to hepatitis and acute and chronic encephalomyelitis [24-28]. It is recognized that there are at least three major mechanisms of the formation of immune-mediated lesions in CNS. They include: a) a systemic inflammatory response syndrome (SIRS) which occurs as a result of an excessive host response to the infection and leads to the dysfunction of various organs, including CNS; b) a direct viral infection of CNS immune cells, such as astrocytes, microglia, and macrophages, leading to the local production of pro-inflammatory cytokines IL6 , TNF- $\alpha$, IL-1 $\beta$, and IL12, as well as some toxic agents or subsequent tissue damage via the recruitment and activation of other immune cells and induction of apoptosis [29]; and c) generation of an autoimmune reaction by an adaptive immune response directed against host epitopes or proteins, which are either misrecognized by the pathogen-directed antibodies or expressed by damaged tissues (and previously unrecognized by the adaptive immune system) [30-32]. There is also a possibility for the eventual demyelination caused by immune-mediated events, either through T-cells or by means of other cytokine and chemokine pathways [33].

About $40 \%$ (167 out of 417) of COVID-19 patients are known to develop a spectrum of neurological symptoms, such as cerebrovascular diseases, hypoxic/ischemic encephalopathy, impaired consciousness, acute cerebrovascular disease, encephalopathy, acute hemorrhagic necrotizing, corticospinal tract signs, and prominent agitation and confusion(reviewed in [34]). These manifestations prove the presence of a link between the SARS-CoV-2 infection and CNS pathologies and support neurotropism of this virus.

Although the CoVs are not primarily neurotropic viruses and the most published reports defined the respiratory epithelium as their primary target, there is increasing evidence that neurotropism is indeed a common feature of the viruses [35-39]. In addition to the aforementioned MHV, many other members of the $\beta-\mathrm{CoV}$ family have been documented to show neurotropism. This necessitates gaining a clear understanding of whether SARS-CoV-2 can enter the CNS and cause neuronal injury that may result in acute respiratory distress [40] and potentially some other neurological manifestations.

\section{SARS-CoV}

Human tissue studies displayed an abundance of ACE2 receptors in the epithelia of the small 
intestine and lung. These receptors were also identified in vesicular systems, such as venous and arterial endothelial cells and arterial smooth muscle cells in all organs studied, including the brain [41]. In agreement with these observations, ACE2 immunostaining was widely distributed throughout the brain in the transgenic mouse (K18-hACE2 model) expressing human ACE2 [42]. A close look at the antigen and viral kinetics of the SARS-CoV virus in transgenic mice revealed that the infection began in the respiratory epithelium, spread rapidly to the alveoli, entered the brain via the olfactory nerve, and progressively invaded cortical and subcortical regions $[43,44]$. It was also shown that, eventually, the infection extended to several vital brainstem nuclei, such as the nucleus tractus solitarii, dorsal motor nucleus of the vagus, and area postrema.. Since the dorsal vagal complex (DVC) is located in the medulla oblongata, the lowest region of the brainstem that controls several autonomic activities, including orchestration of the cardiorespiratory function (heart and breathing) and food intake, injuries of this specific region of the brainstem could be detrimental to the maintenance of homeostasis and explain the cardiorespiratory disorder. Although the animals intracranially inoculated with low-dose virus were characterized by a limited viral spreading, they rapidly succumbed to infection [44]. In animal models, CoV infection was accompanied by a considerable infiltration of lymphocytes and macrophages in the lungs, resulting in a release of proinflammatory cytokines. This occurred in the brain as well as at the pulmonary level, and within 5 days the subject mice entered a lethargic-like state, which would suggest the involvement of the CNS $[43,32]$. These neuroanatomic seem to point to the idea that the infected organisms die as a result of dysfunction of the cardiorespiratory center in the brainstem [40]. In the past, autopsy results of humans with SARS-CoV infections showed strong evidence of the presence of SARS-CoV by immunohistochemistry, real-time reverse transcription PCR, and electron microscopy [32]. Furthermore, individuals with acute SARS-CoV also exhibited the presence of the virus in cerebrospinal fluid [44].

\section{MERS-CoV}

Very limited data are currently available on the neurological disorders and pathology in humans with the MERS-CoV infection. Although the majority of patients infected with MERS-CoV exhibit predominant pulmonary clinical involvement, there are some patients that exhibit neurologic manifestations, such as ataxia, coma, peripheral nerve symptoms and focal motor deficits $[32,45,46]$. Ex vivo analyses of the MERS-CoV infectivity in various human lung cell lines demonstrated that the virus could infect human neuronal lines [47]. In the hDPP4 transgenic mice model, intranasal MERS-CoV inoculation resulted in infection of both lung and brain by the virus at 3-9-day and 7-9-day post inoculation, respectively, indicating different viral infection kinetics [48]. This may indicate a hematogenous infection route. The brain is (possibly) infected via the olfactory nerves, and thereafter infection is rapidly spread to some specific brain areas, including the thalamus and brainstem [44]. Interestingly, the virus particles were detected only in the brain, but not in the lung, in mice infected with low inoculum doses of MERS-CoV, suggesting that the infection in the CNS played a greater role in the high mortality [49]. Similar to SARS-CoV, MERS-CoV is also known to replicate in human macrophages and dendritic cells, lending additional support to the hematogenous hypothesis [50]. The infected model brain consequences included a mild perivascular cuffing [51], and congestion and dilatation of the cerebral vessels and areas of cellular necrosis in the thalamus, hippocampus, and cerebral cortex $[32,48]$. 


\section{SARS-CoV-2 (COVID-19)}

Although the SARS-CoV-2 is mainly a respiratory pathogen, it can also manifest neurologically, causing encephalitis and epileptic seizures, which makes CNS involvement likely. The reported neurological sequelae of SARS-CoV-2 further suggest that the neurological impact of the virus needs to be examined. In fact, although the ongoing COVID19 pandemic is still relatively young, it has already given rise to many neurological and neuroradiological phenotypes, including ageusia, anosmia, Guillain-Barré syndrome, and even acute necrotising haemorrhagic encephalopathy [52-54].

Mao et al. recently reported that among the patients with a severe form of COVID-19, more than $88 \%$ (78/88) displayed some form of neurologic dysfunction, such as acute cerebrovascular diseases and impaired consciousness [54]. Also, during the current SARSCoV-2 outbreak, a COVID-19 patient was reported to have lost control over breathing [40]. Since many COVID-19 patients suffer acute respiratory failure, clinicians and healthcare professionals must separate them into cases that are either neurologically affected, or do not display any neurological deficits $[55,40]$. It would therefore be beneficial to have have a greater understanding of the possible neuroinvasion of the disease, as it can help in the treatment and prevention of respiratory failure related to SARS-CoV-2 [40].

In a recent report it was demonstrated that both human and mouse olfactory sensory neurons do not express the two key genes involved in SARS-CoV-2 entry, namely TMPRSS243 and $A C E 2$ [56]. However, the olfactory epithelial support cells and stem cells express both of these genes, similar to nasal respiratory epithelium cells [56]. This suggests that the SARS-CoV-2 infection may possess mechanisms that lead to olfactory dysfunction, and also brings into question whether olfactory bulb can serve as an entry point for CoVs. [56,32]. Since the anosmia symptoms appeared in many SARS-CoV-2 infections, these important questions were raised [34]: Does anosmia represent an indication of a SARS-CoV-2 infection in the CNS, or it is a reflection of an impact on the peripheral nervous system? Furthermore, can the olfactory or optic nerves act as conduits for SARS-CoV-2's entry into the CNS? These questions are also in line with the current lack of published data on human neuropathological manifestations of the SARS-CoV-2 infection.

\section{Neurological manifestations in COVID-19 patients}

It is accepted now that the SARS-CoV-2 can reach and be manifested in most human organs and tissues (Figure 1). Mao et al. (2020) investigated the penetration potential of the virus into the central nervous system in 214 patients [54]. Their results show that $36.4 \%$ of the patients had some neurologic abnormalities ranging from some non-specific manifestations, such as headache, seizure, and dizziness to specific manifestations, such as stroke and loss of sense of taste (ageusia) and smell (anosmia) [54]. In fact, gustatory and olfactory dysfunctions are both prevalent in patients with mild-to-moderate COVID-19, despite not having nasal symptoms, whereas some other neurological symptoms and manifestations can be seen in the more severe COVID-19 cases [57-61]. It must be noted here that the more severe neurologic symptoms, such as decreased levels of consciousness, or development of seizures and stroke, were more common in patients in the late stages of the infection, and these symptoms were responsible for the heightened mortality rate in severely affected patients [54]. 
It was also hypothesized that CNS infection with involvement and dysfunction of the cardiorespiratory brainstem centers may contribute to the death of infected animals or patients $[62,40]$. hACE2 transgenic mice that inoculated intracranially or intranasally with virus particles commonly exhibited a disseminated infection of the dorsal vagal complex (area postrema, nucleus tractus solitarius, and dorsal motor nucleus of the vagus) [44]. This complex contains efferent and afferent projections of the vagus nerve to the lungs and respiratory tracts, suggesting that the vagus nerve may also serve as a neuronal route for viral entry into the brain. This leads to the hypothesis that the dysfunction of the cardiorespiratory brainstem centre may be at least partially responsible for the death of $\mathrm{CoV}$ infected animals or patients [62,40]. A cytokine storm with excessive levels of proinflammatory cytokines (IL-6, GM-CSF, IL-2, interferon- $\gamma$, IL-7, inducible protein 10, TNF- $\alpha$, macrophage inflammatory protein 1- $\alpha$, monocyte chemoattractant protein 1 , and monocyte chemoattractant protein 1) may also contribute to the lethality of the COVID-19 infection [63,64]. This is illustrated by recent reports of a COVID-19 patient with an acute necrotizing encephalopathy, a rare complication observed in infections with viruses such as influenza, and related to a cytokine storm in the brain without direct viral invasion $[52,61]$.

A post-mortem histological analysis of the brain of a 71-year-old man who died from complications of COVID-19 revealed the presence of several types of pathological lesions, such as a widespread hemorrhagic and lesion of white matter with a clusters of macrophages, necrotic blood vessels and perivascular inflammation, acute axonal injury, demyelination, a marked lesions of central axonal injury, associated extravasated blood, and surrounding myelin loss [65]. Despite all of these dramatic neurological manifestation in this patient, a routine histological examination of the olfactory bulb/nerve revealed only aging-related corpora amylacea [65]. More globally, the presence of brain tissue edema and partial neuronal degeneration were reported in autopsy reports of deceased COVID-19 patients [66].

\section{SARS-CoV-2 cellular entry receptors}

It appears that all the major requirements for efficient hijacking of the nervous cells/tissues by the SARS-CoV-2, which caused the COVID-19 outbreak, are in the place. This includes utilization of the ACE2 (which is present on the surfaces of the cells in a wide variety of human tissues, including the brain) as a cellular entry receptor and the presence of the spike glycoprotein possessing affinity for ACE2, which is 10-20 fold higher than that of the SARSCoV spike protein $[67,68]$. All this indicates that SARS-CoV2 may have higher neuroinvasive potential compared to previous HCoVs. It was also shown that the SARS-CoV-2 receptor ACE2 is expressed in endothelial cells of cerebral capillaries, and within the brain parenchyma in both neurons and microglia [69]. However, there is no complete expression profile of the catalytic enzymes that are required for CoV entry, such as transmembrane serine protease 2 (TMPRSS2) and Furin, on the surface of the nervous tissue cells, from where the COVID-19 can inter to the human nervous system.

Recent studies showed that a subset of COVID-19 patients exhibit altered olfactory function [70-72]. Single-cell and bulk RNA-Seq datasets from human nasal biopsy [73] were analyzed to identify the cell types in the human olfactory neuroepithelium (which is an extracranial site supplying input to the olfactory bulbs of the brain) and in the olfactory bulb that express cell entry molecules (ACE2 and TMPRSS2, as well as Furin) that mediate infection by SARSCoV-2 [56]. This was further complemented by the analysis of the single-cell RNAseq data 
from whole mouse olfactory bulb from juvenile mice (age postnatal day 26-29) [74] as well as single-cell RNAseq data from the olfactory bulb from the adult male mice (8-12 weeks-old) [56]. These analyses revealed that two key genes involved in SARS-CoV-2 entry, namely ACE2 and TMPRSS2, were expressed in the samples from the whole olfactory mucosa in mouse and human in addition to the thiol proteases cathepsins Ctsb and Ctsl [56]. However, neither olfactory sensory neurons nor olfactory bulb neurons expressed these genes (with the exception of cathepsins Ctsl), which instead were expressed in several stem, perivascular, and support cells [56]. Such results suggest that anosmia and related disturbances in odor perception in COVID-19 patients could be associated with the SARS-CoV-2 infection of nonneuronal cell types [56].

Vavougios proposed that the furin-like cleavage site of the $\mathrm{CoV}$ spike protein could be an important determinant for the neurotropism of this virus (i.e., its ability to infect nerve tissue) $[75,76]$. In fact, it was found that cleavage of the S-protein by furin or furin-like proteases is important for the invasion and virulence of SARS-CoV and MERS-CoV [77]. Furthermore, the proteases determine the host tissue tropism and specificity of these CoVs [77], letting them infect the nervous system via membrane fusion. However, additional studies are necessary to determine if the furin-like cleavage site on the spike protein of SARS-CoV-2 plays a certain role in its invasion of the nervous system. Another important issue that also requires careful future analysis is the presence and sustainability of the nervous system damage after the cure of the COVID-19 infection. This became especially troublesome in light of the fact that the anosmia and ageusia, which are frequently observed among COVID-19 patients, also serve as characteristic and prodromal non-motor manifestations of Parkinson's disease [78,79].

It is also possible that other SARS-CoV-2 receptors may exist, or another cellular entry mode is utilized by SARS-CoV-2 for hijacking the nervous cells/tissues. These possibilities were supported by [80], whose analysis suggested the presence of a different receptor repertoire potentially involved in the SARS-CoV2 infection at the epithelial barriers and in the immune cells, such as the co-expression of ACE2, CD147 (BSG), and CD26 (DPP4). Changes in the expression of these receptors related to gender, age, smoking, and obesity, as well as to the status of the disease, may further contribute to COVID-19 severity and morbidity patterns [80]. Using a combination of structural and molecular modelling approaches, Fantini et al. (2020) revealed that the sialic acids linked to host cell surface glycoproteins and ganglioside can also serve as an additional cellular entry route for SRSR-CoV-2 [81], similar to influenza virus, SARS-CoV, and HCoV OC43 [82,83]. A new type of ganglioside-binding domain (111-158) at the tip of the N-terminal domain of the SARS-CoV-2 S protein was identified, which is fully conserved among clinical isolates worldwide, and sialic acid and ganglioside bind chloroquine with high affinity [81].

Although there is a 77\% sequence identity between SARS-CoV and SARS-CoV-2, Hassanzadeh et al. (2020) discovered that the SARS-CoV-2 S protein has a slightly higher positive charge than SARS-CoV. This is because it has five less negatively charged residues andfour more positively charged residues, which may be why the protein has a higher affinity for negatively charged regions of other molecules in both specific and non-specific interactions [84]. Analysis of the peculiarities of the S protein binding to the host ACE2 receptor showed a $30 \%$ higher binding energy for SARS-CoV-2 than the SARS-CoV S protein [84]. Therefore, SARS-CoV-2 is expected to have higher efficiency than SARS-CoV in reaching the brain after entering through the cells [84]. 


\section{Cigarette smoking, COVID-19 infectivity and neurotropism}

Cigarette smoke has been shown to increase patient susceptibility to COVID-19, with smokers suffering from the disease being far more likely to develop critical illnesses [85-87]. One study of 1,099 COVID-19 patients revealed that only $4.7 \%$ of non-smokers required mechanical ventilation, were admitted to an intensive care unit (ICU), or died, compared to $12.3 \%$ of smokers [1]. Although the exact mechanism for such an association is uncertain, one of the potential explanations can be found in the fact that cigarette smoke can increase the levels of ACE2 expression in the lungs of mammals [88]. In the case of SARS-CoV infection, ACE2 levels may influence the progression of the disease: within a group of mice engineered to express human ACE2, mice with the highest levels of ACE2 mRNA displaying the shortest survival time after being exposed to SARS-CoV [43].

In agreement with this model, analysis of the datasets of large, small, and bronchial airway epithelium of current and former smokers revealed a noticeable upregulation of pulmonary ACE2 gene expression in all datasets of smokers compared to non-smokers, irrespective of tissue subset [89]. Another study also showed that ACE2 expression in the lower airways is upregulated by active cigarette smoking and COPD, which might help explain the higher risk of serious COVID-19 in patients that smoke [90]. Interestingly, in this study, smoking status was significantly related to the levels of the ACE2 gene expression in the airways of these participants, where current smokers showed a significantly higher gene expression than neversmokers, whereas former smokers' levels were between current and never-smokers [90]. This ACE2 overexpression in human bronchial epithelial cells is mediated by nicotine exposure specifically through the $\alpha 7$ subtype of nicotine acetylcholine receptors ( $\alpha 7-n A C h R)$ [91], which was significantly correlated with expression of $C H R N A 7$ gene encoding the $\alpha 7$-nAChR. The levels of the CHRNA7 expression were also correlated with the body mass index, raising an intriguing scenario, where the nicotine receptor mediation of ACE2 may also be related to the high proportion of obese individuals among the COVID-19 cases [92]. Further support is given by the fact that cigarette smoke might cause a dose-dependent upregulation of ACE2, in both rodent and human lungs [93].

There are also reports indicating that smoking may result in higher levels of androgren hormones like testosterone. The androgen receptor has been shown to increase the expression of TMPRSS2 [94], and sex steroid modulation of TMPRSS2 serves as a possible mechanism that may explain the differences in SARS-CoV-2 infection rates between females and males [95]. In line with these observations, RNA-sequencing data analysis for lung and oral epithelial tissues of human COVID-19 patients clearly demonstrated that both TMPRSS2 and ACE2 were significantly upregulated among smokers versus non-smokers [96]. It was also found that there was a correlation between the smoking-mediated upregulation of the androgen pathway and the upregulation of ACE2/TMPRSS2 expression, and that the androgen receptor gene and ADAM17 (a key mediator of ACE2 activity) were upregulated in smokers [96]. Furthermore, smoking was shown to induce furin upregulation, although to a lesser degree than ACE2 [89].

Taken together, these observations support the idea that epithelial cells may be more susceptible to the COVID-19 virus as a result of smoking [96]. But what one can say about smoking and neurotropism of CoVs? ACE2 expression in human brain vessels was significantly elevated by cigarette smoke extract (CSE) treatment. Furthermore, it was found that ACE2 expression is increased in vessels exposed to diabetes or smoking and in ischemic brains, which leads to them being more susceptible to infection. Also, ACE2 expression was upregulated in primary cultured human blood vessels with diabetes when compared to healthy 
vessels [97]. Therefore, the regulation of ACE2 expression by cigarette smoke in the brain likely has a significant effect on SARS-CoV-2 susceptibility, and might facilitate viral dissemination [93]. The harmful effects of CSE on the BBB can upregulate several genes related to inflammation, such as VCAMI and ICAM1, which also have destructive effects on the BBB [97].

\section{Nervous system access routes of $\mathrm{HCoVs}$ and related pathophysiology}

Coronaviruses (CoVs) are primarily not neurotropic viruses, and their primary target is the respiratory epithelium. However, although the angiotensin-converting enzyme-2 (ACE2), which serves as a major receptor for Severe Acute Respiratory Syndrome coronavirus (SARS$\mathrm{CoV}$ ) and SARS-CoV-2, and which is an enzyme attached to the cell membranes of cells in the arteries, lungs, kidney, heart, and intestines, it can also be found in glial cells in spinal and brain neurons [98]. SARS-CoV and SARS-CoV-2 can therefore use these receptors to enter, attach, multiply, and damage the neuronal tissue. Studies on mice also show that SARS-CoV can enter the brain through the cribriform bone or through a retrograde transfer via the olfactory epithelium, and in seven days can reach the brain. The virus can also enter the brain directly due to a disruption of the $\mathrm{BBB}$ during the viremia phase of the disease. The invasion of peripheral nerve terminals by $\mathrm{CoV}$ is another postulated mechanism, after which the virus enters the CNS through the synapse connected route. Given that SARS-CoV-2 is very similar to SARS-CoV, it is likely that it can invade the CNS using the same methods as SARS-CoV.

However, though the receptor's expression pattern can determine which cells can be infected, not all cells that express the receptor, or even cells with the highest receptor expression, are necessarily the primary targets of the viral attack. This can be exemplified by the mouse hepatitis virus (MHV) studies, where the MHVR receptor is highly expressed in the liver, but barely so in neurons. On the other hand, the MHV strain JHM.SD, which is highly neurovirulent, is not able to replicate in the liver during viral infection, [99]. Mapping the viral tropism in vivo and the virulence factors that contributed to pathogenesis required considerable time and energy. Surprisingly, it was revealed that tissue tropism was not solely impacted by the viral spike protein, but instead by other viral "background genes," such as replicase and nucleocapsid, in addition to different viral accessory genes, in which can also be used for the determination of tropism (reviewed in [100]). Pathogenesis can therefore not be directly inferred from the knowledge of the receptor and spike protein alone. Future studies on SARSCoV-2 will define tissue tropism and whether it parallels SARS-CoV or not [101].

Let us look more closely on the potential routes for SARS-CoV-2 entry into the CNS (see Figure 2). The observation of the presence of the viral-like particles in brain capillary endothelium and their active budding across the endothelial cells strongly suggested that the hematogenous route and the endothelial bed were the most likely pathway to the brain [102]. Expression of the human receptor ACE2, which serves as a receptor and the binding target for the trimeric spike protein of SARS-CoV-2, by the vascular endothelium [41] also supported this interpretation [102]. However, other routes of the SARS-CoV-2 CNS entry, such as retrograde axonal transport from the olfactory bulb, cannot be ruled out. In line with this idea, there is experimental evidence showing the capability of neuroinvasion by HCoV-OC43 and SARS-CoV in mice infected intranasally with these viruses [64]. It was hypothesized that this could happen as a result of a disruption of the nasal epithelium and the resulting neuronal 
dissemination of the virus [64]. This idea would explain the onset of early signs of anosmia as a precursor to other neurological symptoms. Furthermore, based on the previously observed ability of other viruses such as SARS-CoV in the brainstem to induce the dysfunction of the cardiorespiratory center [44], it was hypothesized that the respiratory failure of COVID-19 patients may be governed by the neuroinvasive potential of SARS-CoV-2[40,102]. Therefore, COVID-19 might cause respiratory failure and death not through damage to the lungs, but by affecting the brain.

Baig et al. have suggested [55] that the SARS-CoV-2 may access the brain using the same "transcribrial route" defined for other pathogens that target the CNS (such as Naegleria fowleri causing meningoencephalitis) [103] and for the delivery of drugs and embryonic stem cells to brain [104]. It is also likely that the SARS-CoV-2 dissemination across the cribriform plate of the ethmoid bone or in the systemic circulation may result in cerebral involvement, similar to what was reported in patients affected by SARS-CoV [44]. As per Baig et al., by virtue of its presence in general circulation, SARS-CoV-2 can be passed into cerebral circulation, where it will have a chance to interact with ACE2 expressed in the capillary endothelium, and thereby to infect cells there, causing damage to the endothelial lining and providing viral access to the brain [55]. Importantly, SARS-CoV-2 interaction with the ACE2 receptors expressed in neurons can lead to virus entry and begin a cycle of viral budding and neuronal damage without substantial inflammation, as was reported previously in SARS-CoV cases [44]. It should be noted that well before the anticipated neuronal damage occurs, the endothelial ruptures in cerebral capillaries, together with bleeding within the cerebral tissue, can be fatal in COVID19 patients [55]. SARS-CoV-2's movement to the brain via the cribriform plate located near the olfactory bulb can act as an additional path that would allow the virus to reach and affect the brain. All this clearly indicates that the observation of hyposmia or an altered sense of smell in an early and uncomplicated stage of a COVID-19 patient should be thoroughly investigated for CNS involvement [55].

\section{Olfactory route}

There is a growing interest in the study of the olfactory epithelium (OE). It is the most proximal axonal area of the human brain, with neurons that can be regenerated. Many studies show a strong link between olfactory deficiency (for example, loss of smell) and neurodegenerative diseases such as (Alzheimer's and Parkinson's diseases, AD and PD, respectively). The main neurological manifestation of COVID-19 is the loss of taste or smell. Since most instances of smell loss occur without significant rhinorrhea or nasal congestion the virus likely targets the chemical senses in ways that are different from those utilized by other common cold-causing agents or endemic coronaviruses [70]. Therefore, it seems that the olfactory route represents a logical pathway of SARS-CoV-2 entry into the CNS. In fact, analysis of SARS-CoV-2 prevalence in clinical specimens showed that the viral copy number found in nasal swabs is $\sim 200$ fold higher than those found in the bronchoalveolar lavage or pharyngeal swabs $[105,106]$. The utilization of the olfactory route is further supported by the fact that issues with smell have been reported internationally, reporting a prevalence as high as $85 \%$ in a large, multicenter European survey [107]. Furthermore, high intensity ACE2 staining was detected in olfactory mucosal biopsies, with a 200-700 fold ACE2 enrichment in the olfactory neuroepithelium (sustentacular cells) relative to the nasal respiratory or tracheal epithelial cells [108]. This cellular tropism of SARS-CoV-2 may underlie its high transmissibility and 
association with dysfunction of olfactory neuroepithelium receptors in the nasal and oral mucosa, and also suggests the existence of a viral reservoir that may be a good candidate for intranasal therapy. On the other hand, ACE2 was not found in immature and mature olfactory neurons [108]. Taken together, these observations of the enhanced expression of ACE2 localized to the olfactory neuroepithelium of the human airway suggests that COVID-19 infection and replication may take place in the apical layer of nasal and olfactory mucosa, resulting in olfactory loss and acting as a possible entry point of the virus into the CNS, causing neurological symptoms [54,108]. Furthermore, although the post-mortem examination showed no inflammatory infiltrates or neuronal necroses in the brains of the deceased COVID-19 patients analysed histologically, and although the SARS-CoV-2 RNA copy numbers were predominantly low in the brain, the corresponding values detected in the olfactory bulb were higher than those in the brainstem, supporting the hypothesis of the viral entry into the brain via the lamina cribrosa [109]. In light of the facts that the swabs from olfactory sustentacular cells bear 200-fold SARS-CoV-2 RNA copy numbers compared to those found in the bronchoalveolar lavage, and that the olfactory sustentacular cells express 200-700-fold more ACE2 relative to the nasal respiratory or tracheal epithelial cells, a fundamental question arose: are there local structures responsible for the COVID-19-associated loss of smell and taste? This seems to be the case, since the microenvironment becomes favourable for the release and/or recruitment of inflammatory leukocytes and cytokines, and subsequently acute reversible or chronic impairment of these chemosensory functions [70,110,111].

\section{Blood-nervous system barriers (BNSBs)}

Humans have evolved highly sophisticated barrier systems to prevent the entry of potentially harmful substances into the nervous system. The CNS contains four types of such barriers, which are the blood-brain-barrier (BBB), the choroid plexus (CP, which is a vascular tissue found in all cerebral ventricles that produces the cerebrospinal fluid (CSF) of the CNS) bloodcerebrospinal-fluid-barrier (BCSFB), the meningeal-brain-barrier (which consists of the three membranes that envelop the brain and spinal cord, with the meninges in mammals being the dura mater, the arachnoid mater, and the pia mater), and the lymphatic vessel brain barrier. In addition, there is one more barrier of the peripheral nervous system, namely, the blood-nerve barrier. However, some viruses are able to directly manipulate the BBB or BCSFB to enter the CNS, whereas others hijack host immune cells or travel within peripheral nerves. The bloodnervous system barrier (BNSB) may represent the main route of the SARS-CoV-2 for breaching the nervous system (CNS and PNS).

The nervous system has barriers that isolate it from the bloodstream and help it achieve the complex microenvironment control necessary for complex neural signalling. Although all these main physiological nervous barriers differ in location, size, morphology, and function, their main structural units are the epithelial or endothelial cells, which are known to express both ACE2 and TMPRSS2. The vascular endothelial cells constitute the interface between the interstitial fluid of the CNS tissue and the blood. The blood-cerebrospinal fluid barrier (BCSFB) comprises a single layer of endothelial/epithelial cells at the choroid plexus or meninges. It is a fluid-brain barrier consisting of two membranes that separate blood from CSF at the capillary level, and CSF from brain tissue. Epithelial cells separate the plexus or meningeal blood from the CSF. The BCSFB regulates most of the exchange of ions, water, and other substances that can be found between blood and CSF. A few localized brain regions, such as the pineal and the area postrema, are called circumventricular organs (CVOs) and lack the vascular BBB, but rather have a barrier of ependymal cells between the CSF and CVO tissue, and of tanycytes between adjacent brain tissue and the CVO. Therefore, the BCSFB represents 
a regulatory interface comprising a monolayer of cells that separates the blood from the fluids of the CNS [112,113].

As most neurological disorders in COVID-19 patients are demonstrated in somewhat aged patients, the well-documented effects of age on the endothelial/epithelial barriers and specifically of the BNSB should be kept in mind. The exponential decline of integrity/permeability of these barriers is linked to age as reviewed in detail by Delaney and Campell [114]. It is becoming increasingly evident that the pericytes are susceptible to agedependent deterioration at the BBB. Breakdown of the paracellular pathway, pericyte loss, and transcellular permeability can exacerbate the events linked with age, and can lead to the extravasation of blood-borne material. The susceptibility of endothelium towards many intrinsic destructive agents is known to increase with aging [114]. Again, these facts may provide some explanations of why the SARS-CoV-2 particles were detected in all post-mortem nervous tissue biopsy examined (see Table 1).

\subsection{The blood-brain barrier $(\mathrm{BBB})$ route}

The BBB, located in the brain microvessels, is the largest brain barrier in terms of length, (close to $650 \mathrm{~km}$ ) and surface $\left(10-20 \mathrm{~m}^{2}\right.$ ). It protects the brain from exogenous and circulating threats and maintains brain homeostasis [115]. Despite its size, various neuroinvasive viral pathogens, such as rabies, HIV-1, West Nile, Zika, and influenza are able to breach the BBB [116-125]. These viruses negatively affect the barrier by direct interaction with the endothelial cells, as well as by induction of host immune responses that result in elevated expressions of proinflammatory chemokines, cytokines, and cell adhesion molecules that lead to a deterioration of the barrier's functional and structural integrity [126]. A disruption of the BBB can result in the crossing of viral particles and infected immune cells, which can further elevate the levels of inflammatory mediators [126-129]. It is therefore possible that SARS-CoV-2 can use these mechanisms of neuroinvasion, and may also primarily enter the CNS by crossing the BBB. Interactions between SARS-CoV-2 and components of the BBB therefore have the potential to significantly impact neuropathogenesis. Further support to the BBB route hypothesis is given by the facts that BBB is disrupted in hypertension [130] and hypertension is a frequent comorbidity for COVID-19 [131-135].

The BBB is a highly restrictive barrier that protects the CNS from aberrant immune responses and pathogens in the periphery. BBB is formed by the brain endothelial cells lining the cerebral microvasculature with about 50-100 times tighter contacts than that in the peripheral microvessels and astrocytes, which are in direct contact with the endothelial cells [136]. Astrocytes play a central role in maintaining homeostasis within the CNS by regulating the integrity of the BBB, as well as by controlling the uptake of excess neurotransmitters and other extracellular factors that may perturb neurotransmission [136]. It was also pointed out that several biomolecules, such as Endothelin-1 (ET-1), Glutamate, IL-1 $\beta$, IL-2, IL-6, TNF $\alpha$, Macrophage inflammatory proteins MIP-2, and nitric oxide might modulate the BBB permeability, with at least some of these biomolecules being released by astrocytic glial cells [136].

Notably, a deregulated immune response serves as an important mediator of COVID-19 mortality [137], as critical illnesses are more likely to develop in patients with heightened levels of inflammatory cytokines [138-143]. These conditions are referred to as "cytokine storms" and result in an increase in vascular permeability, which facilitates immune cell efflux into affected tissues, while also possibly worsening pneumonia [144]. Importantly, most of the proteins that were shown to modulate the BBB permeability [136] are part of the cytokine storm 
in severe COVID-19 cases. One of the outputs of the systemic inflammation is known to cause vascular injury, including breakdown of collagen and permeability of BBB. For example, influenza A virus infection disturbs BBB via the systemic elevation of the levels of the matrix metallopeptidase 9 (MMP-9) [145-147], which is a member of the family of zincmetalloproteinases involved in the degradation of the extracellular matrix and which breaks collagen present in the basal membrane of every arterial wall, thereby leading to a high collagen turnover in systemic circulation [148] and to the increase in BBB permeability. Such BBB permeability elevation represents a link between MMPs (specifically MMP-9) and CNS disorder $[149,150]$.

Under physiologic conditions, the BBB is relatively impermeable, though recently the list of biomolecules capable of modulating the permeability, integrity, and tightness of the BBB was extended by inclusion of the SARS-CoV-2 spike protein [151]. It was shown here that introduction of the viral spike proteins into the model systems recapitulating the essential features of the BBB resulted in a breach of the barrier. Furthermore, SARS-CoV-2 spike protein was shown to increase the MMP3, CCL5, CXCL10, ICAM-1, and VCAM-1 (which are cell adhesion molecules, CAMs) gene expression levels, alter mRNA levels of interleukins IL$1 \beta$ and IL-6, and trigger a pro-inflammatory response on brain endothelial cells that may further contribute to an altered state of BBB function [151]. These observations were used to support a hypothesis that SARS-CoV-2 is potentially a neuroinvasive virus since it can turn on the machinery to enable the migration of infected immune cells into the brain parenchyma [151]. In blood vessels, the increase of VCAMI and ICAMI in response to the pro-inflammatory cytokines plays a crucial role in the adhesion of leukocytes, including macrophages and neutrophils, with the end result being disruption of the BBB and inflammation of the brain [97]. Viral gene products can also contribute to the BBB breakdown through up-regulation of many biomarkers [152]. CXCL8, CXCL10, CXCL13, VCAM-1, MMP2, MMP14, and IL-6 were shown to be over-expressed in COVID-19 patients [153]. All of these molecules were demonstrated to increase the permeability of the endothelial/epithelial cell barriers (especially in nervous system) or decrease its electric resistance and/or cleave the tight junction proteins and promote leukocyte extravasation from the blood (reviewed in detail in [152]).

Therefore, SARS-CoV-2 is able to breach the BBB during the course of ongoing infection. Then, similar to the earlier observations for SARS-CoV [154], interactions of SARS-CoV-2 S protein with ACE2 in multiple brain regions allows the virus to infect the brain. More severe cases of COVID-19 may result in higher probabilities of BBB disruption, which can be associated with strong immunologic responses, such as the cytokine storm pathologies or some co-infection, or other comorbidities.

Therefore, viruses might invade the CNS by entering through the endothelial cells of the BBB and the blood-CSF barrier in the choroid plexus. Studies conducted by Bulfamante et al. [155] and Paniz-Mondolfi et al. [102] strongly support this hypothesis. The authors captured the viral particles using a cytoplasmic vacuole at the endothelial neural cell interface in a transmission electron microscope, suggesting that SARS-CoV-2 is able to bind to vascular endothelium, penetrate the $\mathrm{BBB}$, and invade nervous tissues through hematogenous pathways.

The presence of SARS-CoV-2 in the brain was demonstrated by transmission electron microscopy analysis of the sections obtained at post-mortem that revealed the presence of 80 to $110 \mathrm{~nm}$ viral particles in frontal lobe brain sections [102]. The presence of the virus there was further confirmed by testing the frozen front lobe tissue via running in parallel brain samples in 4 RT-PCR assays that targeted different regions of the viral genome, ORF1/a and $E$ genes, $N 1, N 2, N 3, N 2$ and $E$ genes, and $O R F 1 a b$ and $S$ genes. SARS-CoV-2 was detected in the brain tissue, while the RT-PCR testing did not detect SARS-CoV-2 in a post-mortem 
cerebrospinal fluid (CSF) samples [102]. However, other reports detected SARS-CoV-2 in the CSF samples of the COVID-19 patients from three different countries (USA, Brazil, and Japan).

In the first report, PCR detected the SARS-CoV-2 in the CSF of a 40-year-old Los Angeles resident with type 2 diabetes mellitus and obesity, who developed fever and temporary loss of consciousness (syncope) and was admitted for encephalitis [156,157]. In the second report, the SARS-CoV-2 genome was detected and sequenced in a 42 year-old resident of São Paulo with suspected demyelinating disease [158]. In the third report, RT-PCR analysis detected SARSCoV-2 in the CSF of a Japanese patient with meningitis/encephalitis associated with SARSCoV-2 [159]. Although SARS-CoV-2 RNA was found in the CSF, no reports have detected and/or demonstrated the presence of the viral particles in the CSF of COVID-19 patients. Therefore, the RT-PCR positivity of the CSF samples for the SARS-CoV-2 RNA does not necessarily imply the presence of the entire infectious viral particles in there, as clearly demonstrated by the inability to detect the full-genome consensus in the CSF samples, where only 1580-nucleotides of two fragments from ORF1a were sequenced [158]. Despite all this, the data collected so far support the BBB breach as an important SARS-CoV-2 entry route. Furthermore, it is possible that the SARS CoV-2 infection could be more persistent in the CNS, which is clearly an immunoprivileged site [158]. Another possibility for the SARS-CoV-2 to cross the $\mathrm{BBB}$ and pass into the $\mathrm{CNS}$ is via the infection of the blood cells capable of $\mathrm{BBB}$ crossing [160].

Observation of the virus-like particles in blood vessel endothelial cells of BBB may point to a hematogenous route of entry of the virus into the nervous system [102]. Neuronal retrograde and hematogenous routes were considered for the entry of neurotropic respiratory viruses into the CNS [64]. In the hematogenous route, viruses gain access to the CNS by using inflammatory cells as "Trojan horses", or by infecting endothelial cells of the BBB or epithelial cells of the blood-cerebrospinal fluid barrier in the choroid plexus [64]. In the neuronal retrograde route, viruses undergo retrograde axonal transport to reach the neuron cell bodies in the peripheral and or central nervous system [64]. For example, analysis of the MERS-CoV tissue pantropism (i.e., the ability of a virus to indiscriminately affect many kinds of tissues) has shown that MERS-CoV can enter the bloodstream after endothelial infection in vivo [161]. This hypothesis is further supported by the presence of SARS-CoV-2 in the CSF fluid of a COVID-19 patient presenting viral encephalitis $[162,61]$.

\subsection{The blood-nerve barrier (BNB)}

The mammalian blood-nerve barrier (BNB) is the second most restrictive vascular system after the BBB [163]. Peripheral nerves are structurally divided into three compartments: epineurium, where fenestrated macrovessels directly derived from the extrinsic peripheral nerve blood supply are located; the inner perineurium, which surround the innermost endoneurium compartment of the peripheral nerve. The BNB, formed by the tight junctionforming microvessels within peripheral nerve endoneurium, allows for effective axonal signal transduction. The restricted permeability of this barrier protects the endoneurial microenvironment from drastic concentration changes in the vascular and other extracellular spaces. This barrier supplies cover to the nerves everywhere in human body, constitutes the endothelial cells, and is characterized by very compact structure (Figures 2D1 and 2D2). The analysis of its transcriptome provided insights into the mechanisms of microbial entry from the bloodstream into peripheral nerves, human BNB response to injury, and response to viral infections. 
Inflammatory and metabolic diseases, as well as traumatic lesions of the nervous system, are accompanied by BNB/BDB (blood dorsal ganglion barrier) opening. Opening of the BNB (or permeable/leaky BNB) can be the first sign preceding neuropathic pain, which synchronises with many agents, such as cytokines, growth factors, and microRNAs [164]. Because endothelial cells forming the BNB are the only cells that come into direct contact with the blood constituents in the PNS, endothelial cells can be easily manipulated via system circulation, or indirectly via pericytic activity, including release of various cytokines and chemokines that influence endothelial function [163]. The BNB endothelial cells could transport the IgG, RNA, chemokine, hormones, and delivery drugs, while the large molecular weight antibody subclasses (sIgM and sIgA) do not undergo human BNB transport under standard physiological condition, which may modulate in pathophysiological conditions. BNB endothelial cells respond to physiological cytokine/chemokine stimulus and normal/pathologic leukocyte trafficking across the BNB [165].

Some neurotropic viruses have been found to be able to hijack the peripheral nerve barrier, such as herpes simplex virus and swine hemagglutinating encephalomyelitis virus (HEV) $[37,166,167]$. Although there is no data concerning SARS-CoV-2 trafficking across the BNB, some observations concerning the barrier permeability may point to the ability of SARS-CoV2 , or at least its proteins, to target the $\mathrm{BNB}$ and to modulate its peripheral nerve immunosurveillance in COVID-19 pathogenesis. In fact, several disorders, such as GuillainBarré syndrome (GBS), chronic inflammatory demyelinating polyradiculoneuropathy (CIDP), acute inflammatory demyelinating polyradiculoneuropathy (AIDP), and vasculitic neuropathy $(\mathrm{VN})$ are characterized by hematogenous leukocyte infiltration (predominantly monocytes and T-cells) into peripheral nerves via the $\mathrm{BNB}$, with resultant demyelination and axonal degeneration $[54,59,60,58,61,138,160]$. Therefore, it seems that leukocyte extravasation alone can impact junctional protein expression in the BNB. The chemokine-mediated and/or hyperproduction of interleukin-6 signalling has been implicated in the autoimmune neuropathies pathogenesis [168-170]. Clinically, GBS is characterized by limb or cranial-nerve weakness, loss of deep tendon reflexes, sensory, and dysautonomic symptoms due to peripheral nerves and root demyelination, and/or axonal damage. About $60 \%$ of all GBS are preceded by respiratory or gastrointestinal complications, with a presentation latency varying from 3 days to 6 weeks [170], which corresponds with COVID-19 GBS patients [171]. The suggested infection-mediated immune response that results in higher circulation of pro-inflammatory cytokines $[171,170,59]$ reaches the peripheral nerve through the BNB.

Finally, the GBS and other peripheral nerve symptoms reveal that the peripheral nervous system (PNS) can be hijacked by SARS-CoV-2 through direct attack of microvessel endothelial cells, or indirect attack via immune mediated response. As ACE2 is widely expressed on the epithelial cells of the oral mucosa, SARS-CoV-2 can breach the BNB accessing the CNS via the cranial nerve using axonal transport machinery [172]. The upregulated vascular endothelial growth factor VEGF (C and $\mathrm{A}$ ) is associated with COVID-19 endothelial barrier dysfunction [153,173], and specifically with the BNB [174]. As VEGF is also related to angiopoietins (Ang I and Ang II), accumulation of Ang II facilitates the elevation of VEGF and inversely augments Ang II, which forms a vicious cycle in the release of inflammatory cytokines including TNF- $\alpha$, IL-1 $\beta$, IL-6, IL-8, and ICAM-1, which causes BBB and BNSB disruption [173].

\subsection{Blood-cerebrospinal-fluid-barrier (BCSFB)}


The choroid plexus (CP) of the BCSFB displays fundamentally different properties in comparison to the BBB. With a brisk blood flow (ten times higher than that of the brain) and highly permeable capillaries, the human CP provides the CNS with a high turnover rate of fluid ( $\sim 00 \mathrm{~mL} / \mathrm{day}$ ) that contains peptides, micronutrients, and hormones for neuronal networks. BCSFB cells are the choroid plexus epithelium cells that line the cerebral ventricles and the arachnoid epithelium that line the brain vasculature in the subarachnoid space [112]. CP epithelial is considered to be less electrically resistant compared to the BBB endothelial, and is somewhat "leaky". Therefore, it is the prime target for viral entry into the CNS. Tight junctions (TJs) allow for endothelial cell occlusion and strict permeability by sealing off the intercellular space between the endothelial cells (ECs) lining the microvessel. TJs (e.g., occludins, claudins, and junctional adhesion molecules) are transmembrane proteins that bind intracellularly to the actin component of the filamentous cytoskeleton and extracellularly to identical transmembrane proteins in adjacent ECs [112].

As discussed under the BBB route, the SARS-CoV-2 particle could not be isolated and/or detected in the CSF, although the RT-PCR was positive and two fragments from ORF1a of the 1580-nucleotide were obtained [158,159], the CSF of those patients showed an albuminocytologic dissociation with increased protein level $(98 \mathrm{mg} / \mathrm{dL}$, reference value: 8-43 $\mathrm{mg} / \mathrm{dL})$ and normal cell count $\left(2 \times 10^{6} / \mathrm{L}\right.$, reference value: $\left.0-8 \times 10^{6} / \mathrm{L}\right)[171,175,176]$. Eleven COVID-19-GBS patients from Wuhan, Italy, Spain, and France were analyzed. Although they all had very high concentrations of protein in CSF, in 7 of 11 tested patients, the virus was not detected in the CSF, suggesting that there is no direct root of intrathecal viral replication or infection. However, as intravenous immune globulin (IVIG) helped improve the condition of several patients, and one patient exhibited the presence of antibodies to the ganglioside GD1b, it appears that a post-viral-triggered immune response similar to other post-viral-induced GBS cases or other post-viral autoimmune neurologic disorders occurred [175]. As SARS-CoV-2 spike protein interacts with ganglioside dimers and the GalNAc residue of GM1 for anchoring to cell surface gangliosides, cross-reactivity between epitopes within the SARS-CoV-2 spikebearing gangliosides and signature sugar residues of surface peripheral nerve glycolipids is very likely. Similar molecular mimicry has been shown between peripheral nerve glycolipids and Campylobacter jejuni or Zika virus [175]. This raised many questions, such as: how does this SARS-CoV-2 genomic material reach the CSF? Is it through the BCSFB? Is it accompanied by the delivery of the translated SARS-CoV-2 proteins? Are the increased CSF protein concentration and cell counts in COVID-19 linked with BCSFB and BNB permeability as immune-mediated responses?

\section{Lymphatic brain drainage route}

A third way SARS-CoV-2 can enter the CNS could be via the spreading of the virus in the lymphatic drainage system of the brain [177]. Although the glymphatic vessel structure mainly contains endothelial lining cell systems, this pathway is rather contradictory at the moment, and other researchers do not confirm lymphatic draining entry [2]. The lymphatic/glymphatic brain system (which is a glial-dependent waste clearance pathway in the brain that serves as a "front end" for the waste clearance connected downstream to an authentic lymphatic network) was discovered rather recently [178]. It has a vascular histological structure, which is quite similar to that of the endovascular blood system $[179,180]$. Importantly, endothelial lining cells of this system express both the ACE2 and TPMRSS2 genes, where the SARS-CoV-2 can access it. In line with these features, electron microscopy analysis revealed the presence of viral inclusion structures in endothelial cells [181]. The lymphatic/glymphatic system is different from traditional blood circulation since it is an open, afferent (one-way) system. The major 
function of this system is to collect the soluble waste proteins and metabolic products from the CNS and drain them away. This unidirectionality raises an important and logical question, namely, how can it bring the viral particles to the CNS tissue, being a one-way drainage system? In addition, the lymphatic drainage function is impaired in age-dependent manner [179].

Therefore, the aforementioned BBB route is more favourable for CNS infection by SARSCoV-2, especially in patients with severe COVID-19 complicated with the cytokine storm, which increases the BBB permeability, thereby facilitating the immune cell efflux into the affected tissues. At least in the severe cases, the virus (free or in vacuoles) is disseminated into many organs including the vasculature system, and can cause endothelilitis by attacking the endothelium. This may explain the frequently observed prothrombotic state with in situ clot formation and the impaired microcirculatory function across different organs in COVID-19 patients. Based on these observations it was suggested that one of the approaches to affect the course of COVID-19 would be to take some steps to stabilize the endothelium during viral replication, specifically in vulnerable patients with pre-existing endothelial dysfunctions, which are commonly associated with the male sex, smoking, hypertension, diabetes, obesity, and established cardiovascular disease, all being linked to adverse outcomes in COVID-19 [181].

\section{Peripheral nerve or neuronal retrograde route: Accessing CNS via enteric, lungs, and kidney nerves routes}

Although the direct neuroinvasion via hematogenous spread or migration of SARS-CoV-2 through the olfactory tract are possible infection routes to the CNS [150,3], the virus could also gain access from the periphery [182]. It has been postulated that brain stem invasion may occur via the vagal afferents from the upper airways, lung, and GI [40,182]. Furthermore, one cannot exclude the role of gastrointestinal (GI) tract involvement (a notion giving some tribute to the prospective gut-brain connection). In fact, the GI represents an important but mostly underestimated niche for SARS-CoV-2 replication. This is because the GI epithelium has higher relative expression of ACE-2 receptor than the lungs. Furthermore, SARS-CoV-2 can directly infect the intestinal cells and efficiently replicate there. Finally, it was pointed out that the clinical outcome were worse for COVID-19 patients with concomitant GI symptoms who required mechanical ventilation due to increased acute respiratory distress [183]. One study suggests that SARS-CoV-2 related-diarrhea and the GI dysfunction are not merely accessory symptoms, but serve as a possible marker of the involvement of the enteric nervous system/enteric glial cell (ENS/EGC) in pathogenesis, and suggests an alternative pathophysiological mechanism underlying SARS-CoV-2 neuroinvasion [182]. Here, the gut might serve as the "entrance door", by which viruses may either directly neuroinvade or indirectly immunologically prime the enteric nervous system (ENS) or ascend to the CNS through intestinal vagal afferents [182]. This hypothesis is supported by the fact that there is a strict interconnection between the ENS and the enteric glial cells (EGCs) and that the gut epithelium is part of a neuro-epithelial unit crucial for gut homeostasis [182].

It was also established that in the case of MERS-CoV infection, the enteric involvement could take place before the respiratory infection [184]. Furthermore, brain infection was observed in mice infected with MERS-CoV either intranasally or by intragastric inoculation [184]. Although finding brain infection in mice with intranasal MERS-CoV injection is not surprising and was actuallyexpected, the fact that mice that underwent intragastric inoculation with MERS-CoV showed infectious virions in both brain and lung homogenates 5 days after the 
inoculation was rather surprising [184]. The retrograde axonal transport and trans-synaptic transfer are well-documented for other types of coronavirus such as the avian bronchitis virus and the swine hemagglutinating encephalomyelitis virus (HEV) [166,167].

EGCs express the major histocompatibility complex class II and functionally work as antigen presenting cells for both innate and adoptive immune cells localized in the gut-associated lymphoid tissue (GALT) [185]. GALT houses many types of immune cells, such as T lymphocytes ( $\gamma \delta$ T lymphocytes). Upon activation by viral infection, GALT could initiate many immunological responses, such as transition of native $\mathrm{CD}^{+}$lymphocytes into different subtypes $\left(\mathrm{T}_{\mathrm{h}} 1, \mathrm{~T}_{\mathrm{h}} 2, \mathrm{~T}_{\mathrm{h}} 17, \mathrm{~T}_{\text {reg }}, \mathrm{T}_{\text {sup }}\right.$, and $\left.\mathrm{CD} 8^{+}\right)$. Furthermore, an enormous release of IL-6 and other inflammatory mediators also occurs upon activation, contributing to the acute respiratory distress as observed in the COVID-19-induced cytokine storm [63,182] and to the increase in the endothelium permeability, as aforementioned.

It was shown that the susceptibility to the SARS-CoV-2-inflicted GI damage of the inflammatory bowel disease (IBD) patients is determined by the dysregulated mucosal ACE2 and TMPRSS2 expression in the colon and ileum in IBD [186]. This deregulation was further enhanced by advanced age, smoking, and active disease that served as potential additional risk factors defining the vulnerability of IBD patients to COVID-19 through alterations of receptor expression [186].

Furthermore, it was established that both SARS-CoV and SARS-CoV-2 can efficiently infect enterocyte linage cells in human small intestinal organoids (hSIOs, which are the 3D structures that are grown from adult stem cells (ASCs) and recapitulate key aspects of the organ from which the ASCs were derived) [187]. This efficient infection of enterocytes in hSIOs by SARS$\mathrm{CoV}$ and SARS-CoV-2 was demonstrated by confocal- and electron-microscopy, since the clusters of the extracellular viral particles $(80-120 \mathrm{~nm})$ were detected in the lumen of organoid and in the apical side of enterocytes associated with double membrane vesicles [187]. Could the viral particles of these disintegrated infected cells somehow reach and infect the glial intestinal cells, which are known to express ACE2 and TMPRSS2/furin? Could this scenario be repeated in other organs such as the heart, lungs, kidney, and even cutaneous tissues? Similar to SARS-CoV and SARS-CoV-2 infecting the human intestinal epithelial organoid [187], SARS-CoV-2 was shown to directly infect engineered human blood vessel organoids in vitro [188]. Using both immunochemistry and electron microscopy, SARS-CoV-2 viral particles were found in skin endothelium of patients presenting with chilblains (the painful inflammation of small blood vessels in the skin) [189]. As SARS-CoV-2 multiplies in the vascular cells of the skin area, can it go through the blood withdrawn by a mosquito bite? Ultrastructural examination identified typical $\mathrm{CoV}$ particles characterized by the spike structure in cytoplasm of hepatocytes in two COVID-19 cases [190]. Also, SARS-CoV-2 particles were found in heart, kidney, and lung autopsy of post-mortem samples [191]. Therefore, SARS-CoV-2 may first infect blood vessels' endothelial cells prior to infection of local tissues [188], and then be disseminated into many organs, including the human nervous system $[188,181,189]$.

\section{Somal cargo routes}

\subsection{Macrophage/monocytes cargo route}

Some viruses are neurotropic, being able to invade nervous tissues and cause infections of immune-functioning macrophages, microglia, or astrocytes in the CNS [127,192]. Respiratory viruses may enter the CNS via a hematogenous or a neuronal retrograde route. In the first route, the virus disrupts the nasal epithelium and reaches the bloodstream and leukocytes, and - by 
manipulating the innate immune system - invades other tissues, including the CNS. Furthermore, in this route, leukocytes may act as a reservoir for viral transmission for neuroinvasive CoVs [64]. In the second route, the virus could infect peripheral neurons and access the CNS through retrograde trans-synaptic neuronal dissemination [64]. It is known that both alveolar and interstitial macrophages in the lungs express the ACE2 receptor and the TMPRSS2/Furin proteases, as well as ADAM-17, which acts as sheddase of ACE2. In the presence of all components of viral activation and binding, the virus can replicate in human macrophages [193] and dendritic cells [194], but the mature viral particles could not detected intra or extracellular from both of cells type. Furthermore, the electron microscopic postmortem examination of the lung tissues clearly showed that the SARS-CoV particles and SARS-CoV-2 antigens are present and distributed in both alveolar macrophages, as well as in the lymph nodes and the spleen [195,196]. Previous data from 15 autopsies indicated that the SARS viral particles and genomic sequences were detected in a large number of circulating monocytes, lymphocytes, and lymphoid tissues. They were also found in the mucosa of the intestine, the epithelial cells of the respiratory tract, the neurons of the brain, the epithelium of the renal distal tubules, and macrophages in different organs, suggesting that the virus could infect multiple cell types in different organs [197]. One interesting find was that a large proportion of lymphocytes in the circulation and lymphoid organs contained the virus, as observed in the transmission electron microscopy (TEM) image of a circulating T lymphocyte in a patient who had SARS 6 days after onset of a fever, which may indicate that these circulating lymphocytes carrying viral molecules could reach the CNS and PNS via BBB, $\mathrm{BCSFB}$, or BNB, or through all of these barriers. Based on this interesting result the mechanism of SARS pathogenesis was postulated [197], which appeared to be working until today. It is likely that the viral infection may convert these cells into long living macrophages $(\mathrm{M} \varphi)$ and promote their migration into extra-pulmonary organ/tissues, where they become infected resident cells (viral reservoir) and as inflammatory signals producer, serve as a Trojan horse in other organs [193], with others cell types such as leukocytes, endothelial cells, smooth muscle cells, pericytes, inflammatory cells, neurones or glial cells [198]. A CD68 immunostain revealed that the macrophage infiltrated the cerebral hemispheres and subcortical white matter lesion associated with an axonal injury, and a perivascular acute disseminated encephalomyelitis (ADEM)-like appearance [198,65].

\subsection{Double membrane vesicles cargo route}

Many viruses have been shown to enter the extracellular double-membrane vesicle (EDMV) or exosome avenues during intra-host spreading and synthesis [199]. As previously reviewed in detail, all positive-sense single-stranded RNA viruses (including SARS-CoV and MERS$\mathrm{CoV}$ ) use, redirect, and rearrange host cell membranes as part of the viral genome transcription and replication tactic, harnessing their non-structural protein apparatus nsp1-16 [200]. This tactic allows them to produce double-membrane vesicles of different size and configuration, carrying different levels of viral particle structures, from dsRNA to full mature viral particles, which would be released as extracellular double-membrane vesicles (EDMV) or exosomes during the release from the host cells, or as a result of the post cell-host rapture. SARS-CoV-2 seems to be using a similar avenue of replication and release. This conclusion is based on the careful post-mortem histopathological electron microscopy analysis, and further confirmed using the in vitro SARS-CoV-2 cultured on Vero E6 cells [201]. In fact, electron microscopy revealed that the ultrastructural changes induced by both SARS-CoV and SARS-CoV-2 are 
very similar and take place at comparable times after infection. However, the important differences between the two viruses were the facts that, 1) SARS-CoV-2 generated higher levels of intracellular viral RNA, but 50-fold less infectious viral progeny was recovered from the culture medium; 2) upon passaging in Vero E6 cells, SARS-CoV-2 was apparently under strong selection pressure to acquire adaptive mutations in its spike protein gene [201]. These mutations changed or deleted a putative furin-like cleavage site in the region connecting the $S 1$ and $\mathrm{S} 2$ domains of the $\mathrm{S}$-protein and resulted in a very prominent phenotypic change in plaque assays [201].

Of note, SARS-CoV-2 could infect almost all human body organs and tissues [189,153,200]. The infected cells shedding the exosomes (EDMVs). Furthermore, apoptotic or the diffuse damage of infected cells can lead to the release of their contents in a form of different types of EDMVs containing different viral structures (ranging from viral dsRNA to mature viral particles), to infected the adjacent new cells/tissues and expanded to circulate systemically and disseminate to reaching distant tissues [200]. This hypothesis is supported by [102,189,155], where viral particles were detected in endothelial cells of lungs, kidneys, skin chilblains, and central nervous system of vascular system and organs-crosstalk via the vascular system. The transmission electron microscopy analysis of the post-mortem frontal lobe brain sections showed the presence of viral particles. Pleomorphic spherical viral-like particles having variation in the size and shape were found either individually or within the small vesicles of endothelial cells. The possible active pathogen transcellular penetration (entry-transit process) across the brain microvascular endothelial cells into the neural niche was evidenced as blebbing of viral-like particles coming in/out of the endothelial cells wall. Neural cell bodies exhibited distended cytoplasmic vacuoles containing enveloped viral particle exhibiting electron dense centers with distinct envelope projections ending in round 'peplomeric' structures typical of a coronavirus particle [102]. In the light of these findings, it seems logical that the virus can access the brain directly through the permanent destabilization of the $\mathrm{BBB}$, specifically in patients with very severe viral infection complications accompanied by systemic inflammatory responses, in its free form or vacuolated in double membrane vesicles. In turn, not only viral particles but the peripheral cytokines can gain entry to the CNS, and consequently exacerbate or trigger neuroinflammation that can result in many neurological manifestations, including encephalitis [34].

The isolated EVs released from DENV-2 infected U937 macrophage cell line carrying the viral NS3 protein and different miRs induced an increase in the polarization of the endothelial (EA.hy926) monolayer cells permeability, as well as changes in the expression of ICAM and the VE-cadherin, also leading to an increase in the levels of the IP-10, TNF- $\alpha$, RANTES, IL10, and MCP-1 secretion, even in the absence of the virus [202], suggesting that a proinflammatory status was involved in the endothelial permeability alteration. The miRs most frequently counted within the vesicles obtained from such DENV infected cells include the miR 21, miR 92a, and miR 191, which are strongly associated with many biological pathways involving endothelial cell processes, such as tubular network formation, angiogenesis, and brain microvascular reparation. Such vesicles obtained from the DENV infected cells induced an endothelial activation, possibly determined by the miR that they contain [202].

Different cultured glial cell types released the EDMVs, as well as EDMVs of different sizes were detected in CSF. EDMVs are able to cross the BBB in both directions, though it is unclear what the route of transfer is. Also, the peripheral EDMVs can interact with the BBB leading to changes in the barrier's properties. EDMVs can enter the brain parenchyma at the choroid plexus and to facilitate folate import into the brain. Of note, the inflammatory conditions often associated with a leaky BBB facilitated the entry of peripheral EDMVs into the brain, resulting 
in genetic modulation of the target cells of the CNS. These results indicate to that the EDMVs may act as a means of the non-synaptic neuronal cell communication, hence the EDMVs released from neurons are likely involved in the transfer of biomolecules across synapses. Furthermore, all types of macroglia and microglia (phagocytic cells) contributing to CNS tissue homeostasis can secrete EDMVs in the form of exosomes or microvesicles. Microglia (reviewed in $[115,203,204])$.

\section{COVID-19 brain access via nicotinic acetylcholine receptor (nAChR)}

It is known that there are functional connections between the ACE2 expression and nicotine exposure in lungs and other organ systems, such as the kidneys and heart. It is likely that because of these functional connections and due to the capability of nicotine to interact with the components of other renin angiotensin system (RAS), smoking can promote COVID-19 cellular entry through the nicotinic acetylcholine receptor (nAChR) signalling pathway. Notably, nAChRs are found on the surfaces of many of the same cells that express ACE2 in the kidneys, lungs, circulation, and in the brain and immune cells [205-208]. Therefore, smoking can impact COVID-19 pathophysiology and have a clinical outcome in several organ systems [209]. As ACE2 is expressed in the brain and functionally interacts with nAChRs [210212], it was hypothesized that if neural cells, such as epithelial cells, are more vulnerable to infection in smokers since nicotine stimulation of the $\mathrm{nAChR}$ can increase ACE2 expression within them [213]. This is an important point since it was shown that mRNA from the closely related SARS-CoV, which also binds ACE2 as a mechanism of cell entry, can be detected in brain and cerebrospinal fluid of infected individuals [214-216]. Furthermore, SARS-CoV's ability to enter neurons was established in the experimental systems using recombinant human ACE2 as the point of entry [44,217]. Considering this scenario, Olds and Kabbani $[213,209]$ asked important questions, such as: can the COVID-19 infection lead to long-term neural damage in both symptomatic and asymptomatic individuals? And if it can, then can the chronic nicotine exposure through smoking habits and addiction increase the risk of the developing of COVID-19-associated neuropathology through interactions between nAChRs and ACE2 in neurons and glia? These important questions still wait for their answers.

\section{Immune-mediated responses and SARS-CoV-2 neurological complications}

Figure 3 represents three escalating phases of COVID-19 disease progression. Increased vascular permeability is also a hallmark change that occurs in the process of a cytokine storm [218]. Although it is known that the cytokine storm (hypercytokinemia) has devastating effects on the respiratory system promoting hyperinflammation and ARDS, and serves as one of the major causes of the fatal outcomes of the disease, the neurological effects of the cytokine storm are less understood. For example, it is not clear if acute or subacute CNS involvement can be caused by the cytokine storm occurring during the final stage of the disease. A case was reported, where a COVID-19 patient developed acute necrotising haemorrhagic encephalopathy after several days with altered mental status, cough, and fever [52]. Although at this stage, the patient demonstrated BBB disruption and the intracranial cytokine storm, no direct viral invasion of the CNS was observed in this case [52].

Importantly, the nervous system seems to be affected by the alterations in the neuroinflammatory mechanisms. In fact, immune mechanisms similar to those initiating the 
cytokine storm in SARS are known to be related to the pathogenesis of multiple neurological diseases, such as cerebrovascular disease, peripheral nervous system disorders, and postinfectious immune-mediated encephalitis, and [219]. Furthermore, a proinflammatory environment is known to play a role in the pathogenesis and progression of a wide range of neurodegenerative diseases, such as AD, amyotrophic lateral sclerosis (ALS), Huntington disease, multiple sclerosis (MS), and PD, where a chronic neuroinflammation causes high levels of cytokines/chemokines [219]. Many of these neurodegenerative diseases are agerelated, and the efficiency of the innate immune response is decreased in older age, increasing the vulnerability of these patients to infection [220]. Older individuals also demonstrate greater severity of the immune response against SARS-CoV-2 infection. All this indicates that there is a potential association of the development and progression of neurodegenerative diseases with SARS-CoV-2 infection that requires careful analysis and better understanding.

Furthermore, although children and adolescents typically demonstrate rather mild COVID-19 course, one cannot exclude the possibility that the SARS-CoV-2 infection may have prospective long term neurological consequences in these population groups as well, triggering some cognitive and psychiatric disorders. In fact, synaptic pruning during childhood and adolescence can be distorted by the immunological alterations associated with SARS-CoV-2 infection, causing problems that will only become apparent in adulthood [219].

Both, adaptive and innate immune responses against SARS-CoV-2 infection and virus itself may cause damage within the CNS or PNS. In fact, both endothelial cells of the BBB and epithelial cells of the BCSFB in the choroid plexus (CP) located in the ventricles of the brain can be targeted by the virus. Furthermore, similar to other viruses [221] SARS-CoV-2 can use leukocytes as an intermediate host cell before spreading into CNS from circulatory system [222]. In fact, such "Trojan horse" mechanism [223], where circulating leukocytes are used by viruses to carry them across the BBB, was described for HIV [224], Zika virus [225], and HCoV-229E [226-228]. In other words, SARS-CoV-2 is potentially able to establish a reservoir in leukocytes converting them into the delivery vehicles disseminating infection outside the respiratory tracts and spreading it into the other tissues including CNS [222].

Transmission electronic microscopy analysis of a brain tissue specimen obtained from the SARS patient succumbed to encephalopathy revealed the presence of SARS-CoV-like viral particle, and a SARS-CoV strain was isolated from this sample, clearly demonstrating the neurotropic potential of this virus [229]. Furthermore, cytokine/chemokine assay showed elevated expression of a cytokine, monokine induced by interferon- $\gamma$ (MIG), and interferon- $\gamma-$ inducible protein 10 in this sample, and the immunohistochemical analysis revealed that a major source for MIG production in the brain was gliocytes [229]. These findings supported the idea that viral entry to CNS might trigger the infiltration of immune cells and the release of cytokines and chemokines, which contribute to the BBB permeability and/or damage.

Therefore, there is clearly an important interplay between the SARS-CoV-2 and the immune system, where dysfunctional immune responses contributes to the disease progression [230]. For example, rapid viral replication and secondary cellular injury during the SARS-CoV-2 promoted the increase in the secretion of inflammatory cytokines, such as IL-4, IL-10, IFN- $\gamma$, IL- $1 \beta$, and TNF- $\alpha$, and the cytokine storm is initiated when the levels of released cytokines are injurious to host cells. The presence of a cytokine storm in severe COVID-19 patients is suggested by their high plasma levels of the inflammatory cytokines [231]. The presence of a cytokine storm combined with the elevated D-dimer (which is a fibrin degradation fragment produced when a blood clot gets dissolved in the body, and which, therefore, serves as a reflection of the presence of thrombosis (blood clotting) and/or thrombotic embolism) and ferritins levels were also reported in SARS-CoV-2 infected patients [232,63]. 
Previous studies on sepsis revealed that sepsis-associated cognitive impairment and other neurological symptoms can be triggered by the cytokine storm-induced BBB disruption and resulting neuroinflammation [233]. This clearly indicates that the activation of the immune system is not only protecting the organism, but also is capable of inducing serious harm, thereby representing a double-edged sword. Contributing factors to the harmful side are the overactivation of the immune system, infection-induced cytokine storm, and the increased immunoglobulin levels in CSF [234]. In line with these mechanisms, neurologic features in severe SARS-CoV-2 infection were shown to be combined with the elevated IgG levels and the presence of the oligoclonal bands (which are defined as at least two CSF electrophoresis bands seen in the CSF samples with no corresponding band present in the serum) in the CSF [234]. Furthermore, the development of acute necrotizing encephalopathy or Guillain-Barré syndrome in virus-infected patients can be associated with intracranial cytokine storms leading to the breakdown of the BBB without direct viral invasion of the CNS [175]. In the classic view, acute lung injury (ALI) and acute respiratory distress syndrome (ARDS) represent an inflammatory disruption of the epithelial and endothelial cellular barriers of the alveolarcapillary unit, with ensuing microvascular hyperpermeability and flooding of alveolar spaces [235].

Another illustration of the double-edged sword concept of immune response activation in SARS-CoV-2 infection is given by the complement system, activation of which represents the first response of the host immune system against SARS-CoV-2 infection. However, "everything is good, which is good in moderation", and uncontrolled complement activation can be harmful as well. In fact, the virus infection of the lungs and other organs can cause complement over-activation leading not only to the acute and chronic inflammation, but to the vasculopathy, e.g., endothelial cell dysfunction, intravascular coagulation, and thrombus formation, thereby contributing to the multiple organ failure and death [236]. In other words, such uncontrolled complement activation might initiate some terminal pathways accounting for what clinicians and pathologists are observing in COVID-19 patients, that is, "although the lungs are ground zero, the virus' reach can extend to many organs, including the heart and blood vessels, kidneys, gut and brain" [236,237]. The activation of complement component C3 exacerbates SARS-CoV-associated ARDS [238], whereas C3-C5 complement deposits are abundant in the lung biopsies from patients with COVID-19 [239]. C5a signalling through its G-protein coupled receptor C5aR1/CD88 increased BBB permeability in neuroinflammatory disease settings in vivo [240]. It is highly likely that "inflamm-aging" (which is a chronic progressive increase in the proinflammatory status associated with the aging process [241]) is correlated with increased risk of a cytokine storm in some critical elderly patients with COVID19 infection [242].

\section{Conclusions}

There are numerous pathways that can be utilized by SARS-CoV-2 to breach the body's defences reach the peripheral nervous system (PNS) and central nervous system (CNS). SARSCoV-2 or its components reach the nervous system through direct contact specifically in severe COVID-19 cases, or indirect contact through multiple mechanisms of immune-mediated responses in mild to moderate COVID-19 cases. We are discussing here that there are at least seven candidate routes, which the mature or immature SARS-CoV-2 components could use to reach the CNS and PNS, utilizing the within-body crosstalk between organs. Obviously, utilization of any one of these routes is sufficient to make SARS-CoV-2 neurotropic. 


\section{Significance Statement}

There are neurological manifestations and complications of the SARS-CoV-2 infection. Therefore, similar to other coronaviruses SARS-CoV-2 is a neurotropic virus. To answer the question on how SARS-CoV-2 infection can reach the human nervous system, we are discussing here seven candidate routes. Among these seven pathways, the blood-endothelialbarrier is the main route for SARS-CoV-2 entry into the nervous system. An important other route is breaching of the BBB, permeability of which can be increased by the cytokine storm leading to neuroinflammation.

\section{Data Availability Statement}

Data sharing not applicable to this article as no datasets were generated or analysed during the current study

\section{References}

1. Guan WJ, Ni ZY, Hu Y, Liang WH, Ou CQ, He JX, Liu L, Shan H, Lei CL, Hui DSC, Du B, Li LJ, Zeng G, Yuen KY, Chen RC, Tang CL, Wang T, Chen PY, Xiang J, Li SY, Wang JL, Liang ZJ, Peng YX, Wei L, Liu Y, Hu YH, Peng P, Wang JM, Liu JY, Chen Z, Li G, Zheng ZJ, Qiu SQ, Luo J, Ye CJ, Zhu SY, Zhong NS, China Medical Treatment Expert Group for C (2020) Clinical Characteristics of Coronavirus Disease 2019 in China. N Engl J Med 382 (18):17081720. doi:10.1056/NEJMoa2002032

2. Li Q, Guan X, Wu P, Wang X, Zhou L, Tong Y, Ren R, Leung KSM, Lau EHY, Wong JY, Xing X, Xiang N, Wu Y, Li C, Chen Q, Li D, Liu T, Zhao J, Liu M, Tu W, Chen C, Jin L, Yang R, Wang Q, Zhou S, Wang R, Liu H, Luo Y, Liu Y, Shao G, Li H, Tao Z, Yang Y, Deng Z, Liu B, Ma Z, Zhang Y, Shi G, Lam TTY, Wu JT, Gao GF, Cowling BJ, Yang B, Leung GM, Feng Z (2020) Early Transmission Dynamics in Wuhan, China, of Novel Coronavirus-Infected Pneumonia. N Engl J Med 382 (13):1199-1207. doi:10.1056/NEJMoa2001316

3. Wu Z, McGoogan JM (2020) Characteristics of and Important Lessons From the Coronavirus Disease 2019 (COVID-19) Outbreak in China: Summary of a Report of 72314 Cases From the Chinese Center for Disease Control and Prevention. JAMA. doi:10.1001/jama.2020.2648

4. Bruckova M, McIntosh K, Kapikian AZ, Chanock RM (1970) The adaptation of two human coronavirus strains (OC38 and OC43) to growth in cell monolayers. Proc Soc Exp Biol Med 135 (2):431-435. doi:10.3181/00379727-135-35068

5. Zhu Y, Li C, Chen L, Xu B, Zhou Y, Cao L, Shang Y, Fu Z, Chen A, Deng L, Bao Y, Sun Y, Ning L, Liu C, Yin J, Xie Z, Shen K (2018) A novel human coronavirus OC43 genotype detected in mainland China. Emerg Microbes Infect 7 (1):173. doi:10.1038/s41426-018-0171-5

6. Woo PC, Lau SK, Chu CM, Chan KH, Tsoi HW, Huang Y, Wong BH, Poon RW, Cai JJ, Luk WK, Poon LL, Wong SS, Guan Y, Peiris JS, Yuen KY (2005) Characterization and complete genome sequence of a novel coronavirus, coronavirus HKU1, from patients with pneumonia. J Virol 79 (2):884-895. doi:10.1128/JVI.79.2.884-895.2005

7. Hierholzer JC (1976) Purification and biophysical properties of human coronavirus 229E. Virology 75 (1):155-165. doi:10.1016/0042-6822(76)90014-3

8. Kaye HS, Ong SB, Dowdle WR (1972) Detection of coronavirus 229E antibody by indirect hemagglutination. Appl Microbiol 24 (5):703-707

9. Fouchier RA, Hartwig NG, Bestebroer TM, Niemeyer B, de Jong JC, Simon JH, Osterhaus AD (2004) A previously undescribed coronavirus associated with respiratory disease in humans. Proc Natl Acad Sci U S A 101 (16):6212-6216. doi:10.1073/pnas.0400762101 
10. van der Hoek L, Pyrc K, Jebbink MF, Vermeulen-Oost W, Berkhout RJ, Wolthers KC, Wertheimvan Dillen PM, Kaandorp J, Spaargaren J, Berkhout B (2004) Identification of a new human coronavirus. Nat Med 10 (4):368-373. doi:10.1038/nm1024

11. Larson HE, Reed SE, Tyrrell DA (1980) Isolation of rhinoviruses and coronaviruses from 38 colds in adults. J Med Virol 5 (3):221-229. doi:10.1002/jmv.1890050306

12. Bradburne AF, Bynoe ML, Tyrrell DA (1967) Effects of a "new" human respiratory virus in volunteers. Br Med J 3 (5568):767-769. doi:10.1136/bmj.3.5568.767

13. McIntosh K, Dees JH, Becker WB, Kapikian AZ, Chanock RM (1967) Recovery in tracheal organ cultures of novel viruses from patients with respiratory disease. Proc Natl Acad Sci U S A 57 (4):933-940. doi:10.1073/pnas.57.4.933

14. Almeida JD, Tyrrell DA (1967) The morphology of three previously uncharacterized human respiratory viruses that grow in organ culture. J Gen Virol 1 (2):175-178. doi:10.1099/0022$1317-1-2-175$

15. Hamre D, Procknow JJ (1966) A new virus isolated from the human respiratory tract. Proc Soc Exp Biol Med 121 (1):190-193. doi:10.3181/00379727-121-30734

16. Esper F, Weibel C, Ferguson D, Landry ML, Kahn JS (2005) Evidence of a novel human coronavirus that is associated with respiratory tract disease in infants and young children. $\mathrm{J}$ Infect Dis 191 (4):492-498. doi:10.1086/428138

17. Gerna G, Percivalle E, Sarasini A, Campanini G, Piralla A, Rovida F, Genini E, Marchi A, Baldanti F (2007) Human respiratory coronavirus HKU1 versus other coronavirus infections in Italian hospitalised patients. J Clin Virol 38 (3):244-250. doi:10.1016/j.jcv.2006.12.008

18. Gerna G, Campanini G, Rovida F, Percivalle E, Sarasini A, Marchi A, Baldanti F (2006) Genetic variability of human coronavirus OC43-, 229E-, and NL63-like strains and their association with lower respiratory tract infections of hospitalized infants and immunocompromised patients. J Med Virol 78 (7):938-949. doi:10.1002/jmv.20645

19. Geller C, Varbanov M, Duval RE (2012) Human coronaviruses: insights into environmental resistance and its influence on the development of new antiseptic strategies. Viruses 4 (11):3044-3068. doi:10.3390/v4113044

20. Zumla A, Chan JF, Azhar EI, Hui DS, Yuen KY (2016) Coronaviruses - drug discovery and therapeutic options. Nat Rev Drug Discov 15 (5):327-347. doi:10.1038/nrd.2015.37

21. Chu H, Chan JF-W, Yuen TT-T, Shuai H, Yuan S, Wang Y, Hu B, Yip CC-Y, Tsang JO-L, Huang X, Chai Y, Yang D, Hou Y, Chik KK-H, Zhang X, Fung AY-F, Tsoi H-W, Cai J-P, Chan W-M, Ip JD, Chu AW-H, Zhou J, Lung DC, Kok K-H, To KK-W, Tsang OT-Y, Chan KH, Yuen K-Y (2020) Comparative tropism, replication kinetics, and cell damage profiling of SARS-CoV-2 and SARS-CoV with implications for clinical manifestations, transmissibility, and laboratory studies of COVID-19: an observational study. The Lancet Microbe 1 (1):e14e23. doi:https://doi.org/10.1016/S2666-5247(20)30004-5

22. Bullen CK, Hogberg HT, Bahadirli-Talbott A, Bishai WR, Hartung T, Keuthan C, Looney MM, Pekosz A, Romero JC, Sille FCM, Um P, Smirnova L (2020) Infectability of human BrainSphere neurons suggests neurotropism of SARS-CoV-2. ALTEX. doi:10.14573/altex.2006111

23. Lane TE, Hosking MP (2010) The pathogenesis of murine coronavirus infection of the central nervous system. Crit Rev Immunol 30 (2):119-130. doi:10.1615/critrevimmunol.v30.i2.20

24. Cheever FS, Daniels JB, et al. (1949) A murine virus (JHM) causing disseminated encephalomyelitis with extensive destruction of myelin. J Exp Med 90 (3):181-210. doi:10.1084/jem.90.3.181 
25. Bailey OT, Pappenheimer AM, Cheever FS, Daniels JB (1949) A Murine Virus (Jhm) Causing Disseminated Encephalomyelitis with Extensive Destruction of Myelin : Ii. Pathology. J Exp Med 90 (3):195-212. doi:10.1084/jem.90.3.195

26. Holmes K, Lai M (1996) Coronaviridae: The Viruses and Their Replication. In: Fields BN, Knipe DM, Howley PM (eds) Fields Virology. Lippincott-Raven Publishers, Philadelphia, pp 10751094

27. McIntosh K (1996) Coronaviruses. In: Fields BN KD, Howley PM (ed) Fields Virology. Lippincott-Raven Publishers, Philadelphia, pp 1095-1104

28. Perlman SR, Lane TE, Buchmeier MJ (1999) Coronaviruses: Hepatitis, peritonitis, and central nervous system disease. In: Cunningham MW FR (ed) Effects of Microbes on the Immune System. Lippincott Williams \& Wilkins, Philadelphia, pp 331-348

29. Li Y, Fu L, Gonzales DM, Lavi E (2004) Coronavirus neurovirulence correlates with the ability of the virus to induce proinflammatory cytokine signals from astrocytes and microglia. J Virol 78 (7):3398-3406. doi:10.1128/jvi.78.7.3398-3406.2004

30. Perlman S, Dandekar AA (2005) Immunopathogenesis of coronavirus infections: implications for SARS. Nat Rev Immunol 5 (12):917-927. doi:10.1038/nri1732

31. Bergmann CC, Lane TE, Stohlman SA (2006) Coronavirus infection of the central nervous system: host-virus stand-off. Nat Rev Microbiol 4 (2):121-132. doi:10.1038/nrmicro1343

32. Natoli S, Oliveira V, Calabresi P, Maia LF, Pisani A (2020) Does SARS-Cov-2 invade the brain? Translational lessons from animal models. Eur J Neurol. doi:10.1111/ene.14277

33. Wu GF, Pewe L, Perlman S (2000) Coronavirus-induced demyelination occurs in the absence of inducible nitric oxide synthase. J Virol 74 (16):7683-7686. doi:10.1128/jvi.74.16.76837686.2000

34. De Felice FG, Tovar-Moll F, Moll J, Munoz DP, Ferreira ST (2020) Severe Acute Respiratory Syndrome Coronavirus 2 (SARS-CoV-2) and the Central Nervous System. Trends Neurosci 43 (6):355-357. doi:10.1016/j.tins.2020.04.004

35. Khan S, Ali A, Siddique R, Nabi G (2020) Novel coronavirus is putting the whole world on alert. J Hosp Infect 104 (3):252-253. doi:10.1016/j.jhin.2020.01.019

36. Wang D, Hu B, Hu C, Zhu F, Liu X, Zhang J, Wang B, Xiang H, Cheng Z, Xiong Y, Zhao Y, Li Y, Wang X, Peng Z (2020) Clinical Characteristics of 138 Hospitalized Patients With 2019 Novel Coronavirus-Infected Pneumonia in Wuhan, China. JAMA. doi:10.1001/jama.2020.1585

37. Li YC, Bai WZ, Hirano N, Hayashida T, Hashikawa T (2012) Coronavirus infection of rat dorsal root ganglia: ultrastructural characterization of viral replication, transfer, and the early response of satellite cells. Virus Res 163 (2):628-635. doi:10.1016/j.virusres.2011.12.021

38. Glass WG, Subbarao K, Murphy B, Murphy PM (2004) Mechanisms of host defense following severe acute respiratory syndrome-coronavirus (SARS-CoV) pulmonary infection of mice. $\mathbf{J}$ Immunol 173 (6):4030-4039. doi:10.4049/jimmunol.173.6.4030

39. Chen N, Zhou M, Dong X, Qu J, Gong F, Han Y, Qiu Y, Wang J, Liu Y, Wei Y, Xia J, Yu T, Zhang X, Zhang L (2020) Epidemiological and clinical characteristics of 99 cases of 2019 novel coronavirus pneumonia in Wuhan, China: a descriptive study. Lancet 395 (10223):507-513. doi:10.1016/S0140-6736(20)30211-7

40. Li YC, Bai WZ, Hashikawa T (2020) The neuroinvasive potential of SARS-CoV2 may play a role in the respiratory failure of COVID-19 patients. J Med Virol 92 (6):552-555. doi: $10.1002 / j m v .25728$

41. Hamming I, Timens W, Bulthuis ML, Lely AT, Navis G, van Goor H (2004) Tissue distribution of ACE2 protein, the functional receptor for SARS coronavirus. A first step in understanding SARS pathogenesis. J Pathol 203 (2):631-637. doi:10.1002/path.1570 
42. Doobay MF, Talman LS, Obr TD, Tian X, Davisson RL, Lazartigues E (2007) Differential expression of neuronal ACE2 in transgenic mice with overexpression of the brain reninangiotensin system. Am J Physiol Regul Integr Comp Physiol 292 (1):R373-381. doi:10.1152/ajpregu.00292.2006

43. McCray PB, Jr., Pewe L, Wohlford-Lenane C, Hickey M, Manzel L, Shi L, Netland J, Jia HP, Halabi C, Sigmund CD, Meyerholz DK, Kirby P, Look DC, Perlman S (2007) Lethal infection of K18-hACE2 mice infected with severe acute respiratory syndrome coronavirus. J Virol 81 (2):813-821. doi:10.1128/JVI.02012-06

44. Netland J, Meyerholz DK, Moore S, Cassell M, Perlman S (2008) Severe acute respiratory syndrome coronavirus infection causes neuronal death in the absence of encephalitis in mice transgenic for human ACE2. J Virol 82 (15):7264-7275. doi:10.1128/JVI.00737-08

45. Kim JE, Heo JH, Kim HO, Song SH, Park SS, Park TH, Ahn JY, Kim MK, Choi JP (2017) Neurological Complications during Treatment of Middle East Respiratory Syndrome. J Clin Neurol 13 (3):227-233. doi:10.3988/jcn.2017.13.3.227

46. Arabi YM, Harthi A, Hussein J, Bouchama A, Johani S, Hajeer AH, Saeed BT, Wahbi A, Saedy A, AlDabbagh T, Okaili R, Sadat M, Balkhy H (2015) Severe neurologic syndrome associated with Middle East respiratory syndrome corona virus (MERS-CoV). Infection 43 (4):495-501. doi:10.1007/s15010-015-0720-y

47. Chan RW, Chan MC, Agnihothram S, Chan LL, Kuok DI, Fong JH, Guan Y, Poon LL, Baric RS, Nicholls JM, Peiris JS (2013) Tropism of and innate immune responses to the novel human betacoronavirus lineage $\mathrm{C}$ virus in human ex vivo respiratory organ cultures. J Virol 87 (12):6604-6614. doi:10.1128/JVI.00009-13

48. Hao XY, Lv Q, Li FD, Xu YF, Gao H (2019) The characteristics of hDPP4 transgenic mice subjected to aerosol MERS coronavirus infection via an animal nose-only exposure device. Animal Model Exp Med 2 (4):269-281. doi:10.1002/ame2.12088

49. Li K, Wohlford-Lenane C, Perlman S, Zhao J, Jewell AK, Reznikov LR, Gibson-Corley KN, Meyerholz DK, McCray PB, Jr. (2016) Middle East Respiratory Syndrome Coronavirus Causes Multiple Organ Damage and Lethal Disease in Mice Transgenic for Human Dipeptidyl Peptidase 4. J Infect Dis 213 (5):712-722. doi:10.1093/infdis/jiv499

50. Zhou J, Chu H, Li C, Wong BH, Cheng ZS, Poon VK, Sun T, Lau CC, Wong KK, Chan JY, Chan JF, To KK, Chan KH, Zheng BJ, Yuen KY (2014) Active replication of Middle East respiratory syndrome coronavirus and aberrant induction of inflammatory cytokines and chemokines in human macrophages: implications for pathogenesis. J Infect Dis 209 (9):1331-1342. doi:10.1093/infdis/jit504

51. Agrawal AS, Garron T, Tao X, Peng BH, Wakamiya M, Chan TS, Couch RB, Tseng CT (2015) Generation of a transgenic mouse model of Middle East respiratory syndrome coronavirus infection and disease. J Virol 89 (7):3659-3670. doi:10.1128/JVI.03427-14

52. Poyiadji N, Shahin G, Noujaim D, Stone M, Patel S, Griffith B (2020) COVID-19-associated Acute Hemorrhagic Necrotizing Encephalopathy: CT and MRI Features. Radiology:201187. doi:10.1148/radiol.2020201187

53. Zhao H, Shen D, Zhou H, Liu J, Chen S (2020) Guillain-Barre syndrome associated with SARSCoV-2 infection: causality or coincidence? Lancet Neurol 19 (5):383-384. doi:10.1016/S14744422(20)30109-5

54. Mao L, Jin H, Wang M, Hu Y, Chen S, He Q, Chang J, Hong C, Zhou Y, Wang D, Miao X, Li Y, Hu B (2020) Neurologic Manifestations of Hospitalized Patients With Coronavirus Disease 2019 in Wuhan, China. JAMA Neurol. doi:10.1001/jamaneurol.2020.1127

55. Baig AM, Khaleeq A, Ali U, Syeda H (2020) Evidence of the COVID-19 Virus Targeting the CNS: Tissue Distribution, Host-Virus Interaction, and Proposed Neurotropic Mechanisms. ACS Chem Neurosci 11 (7):995-998. doi:10.1021/acschemneuro.0c00122 
56. Brann DH, Tsukahara T, Weinreb C, Lipovsek M, Van den Berge K, Gong B, Chance R, Macaulay IC, Chou H, Fletcher R, Das D, Street K, de Bezieux HR, Choi Y, Risso D, Dudoit S, Purdom E, Mill JS, Hachem RA, Matsunami H, Logan DW, Goldstein BJ, Grubb MS, Ngai J, Datta SR (2020) Non-neural expression of SARS-CoV-2 entry genes in the olfactory epithelium suggests mechanisms underlying anosmia in COVID-19 patients. bioRxiv. doi:10.1101/2020.03.25.009084

57. Asadi-Pooya AA, Simani L (2020) Central nervous system manifestations of COVID-19: A systematic review. J Neurol Sci 413:116832. doi:10.1016/j.jns.2020.116832

58. Lai CC, Ko WC, Lee PI, Jean SS, Hsueh PR (2020) Extra-respiratory manifestations of COVID19. Int J Antimicrob Agents:106024. doi:10.1016/j.ijantimicag.2020.106024

59. Ahmad I, Rathore FA (2020) Neurological manifestations and complications of COVID-19: A literature review. J Clin Neurosci 77:8-12. doi:10.1016/j.jocn.2020.05.017

60. Conde Cardona G, Quintana Pajaro LD, Quintero Marzola ID, Ramos Villegas Y, Moscote Salazar LR (2020) Neurotropism of SARS-CoV 2: Mechanisms and manifestations. J Neurol Sci 412:116824. doi:10.1016/j.jns.2020.116824

61. Vonck K, Garrez I, De Herdt V, Hemelsoet D, Laureys G, Raedt R, Boon P (2020) Neurological manifestations and neuro-invasive mechanisms of the severe acute respiratory syndrome coronavirus type 2. Eur J Neurol. doi:10.1111/ene.14329

62. Xia H, Lazartigues E (2008) Angiotensin-converting enzyme 2 in the brain: properties and future directions. J Neurochem 107 (6):1482-1494. doi:10.1111/j.1471-4159.2008.05723.x

63. Mehta P, McAuley DF, Brown M, Sanchez E, Tattersall RS, Manson JJ, Hlh Across Speciality Collaboration UK (2020) COVID-19: consider cytokine storm syndromes and immunosuppression. Lancet 395 (10229):1033-1034. doi:10.1016/S0140-6736(20)30628-0

64. Desforges M, Le Coupanec A, Dubeau P, Bourgouin A, Lajoie L, Dube M, Talbot PJ (2019) Human Coronaviruses and Other Respiratory Viruses: Underestimated Opportunistic Pathogens of the Central Nervous System? Viruses 12 (1). doi:10.3390/v12010014

65. Reichard RR, Kashani KB, Boire NA, Constantopoulos E, Guo Y, Lucchinetti CF (2020) Neuropathology of COVID-19: a spectrum of vascular and acute disseminated encephalomyelitis (ADEM)-like pathology. Acta Neuropathol 140 (1):1-6. doi:10.1007/s00401020-02166-2

66. Xu Z, Shi L, Wang Y, Zhang J, Huang L, Zhang C, Liu S, Zhao P, Liu H, Zhu L, Tai Y, Bai C, Gao T, Song J, Xia P, Dong J, Zhao J, Wang FS (2020) Pathological findings of COVID-19 associated with acute respiratory distress syndrome. Lancet Respir Med 8 (4):420-422. doi:10.1016/S2213-2600(20)30076-X

67. Wrapp D, Wang N, Corbett KS, Goldsmith JA, Hsieh CL, Abiona O, Graham BS, McLellan JS (2020) Cryo-EM structure of the 2019-nCoV spike in the prefusion conformation. Science (New York, NY) 367 (6483):1260-1263. doi:10.1126/science.abb2507

68. Walls AC, Park YJ, Tortorici MA, Wall A, McGuire AT, Veesler D (2020) Structure, Function, and Antigenicity of the SARS-CoV-2 Spike Glycoprotein. Cell. doi:10.1016/j.cell.2020.02.058

69. Yamagata R, Nemoto W, Nakagawasai O, Takahashi K, Tan-No K (2020) Downregulation of spinal angiotensin converting enzyme 2 is involved in neuropathic pain associated with type 2 diabetes mellitus in mice. Biochem Pharmacol 174:113825. doi:10.1016/j.bcp.2020.113825

70. Cooper KW, Brann DH, Farruggia MC, Bhutani S, Pellegrino R, Tsukahara T, Weinreb C, Joseph PV, Larson ED, Parma V, Albers MW, Barlow LA, Datta SR, Di Pizio A (2020) COVID-19 and the Chemical Senses: Supporting Players Take Center Stage. Neuron. doi:10.1016/j.neuron.2020.06.032

71. Altin F, Cingi C, Uzun T, Bal C (2020) Olfactory and gustatory abnormalities in COVID-19 cases. Eur Arch Otorhinolaryngol. doi:10.1007/s00405-020-06155-9 
72. Chung TW, Sridhar S, Zhang AJ, Chan KH, Li HL, Wong FK, Ng MY, Tsang RK, Lee AC, Fan Z, Ho RS, Luk SY, Kan WK, Lam SH, Wu AK, Leung SM, Chan WM, Ng PY, To KK, Cheng VC, Lung KC, Hung IF, Yuen KY (2020) Olfactory Dysfunction in Coronavirus Disease 2019 Patients: Observational Cohort Study and Systematic Review. Open Forum Infect Dis 7 (6):ofaa199. doi:10.1093/ofid/ofaa199

73. Durante MA, Kurtenbach S, Sargi ZB, Harbour JW, Choi R, Kurtenbach S, Goss GM, Matsunami H, Goldstein BJ (2020) Single-cell analysis of olfactory neurogenesis and differentiation in adult humans. Nat Neurosci 23 (3):323-326. doi:10.1038/s41593-020-0587-9

74. Zeisel A, Hochgerner H, Lonnerberg P, Johnsson A, Memic F, van der Zwan J, Haring M, Braun E, Borm LE, La Manno G, Codeluppi S, Furlan A, Lee K, Skene N, Harris KD, Hjerling-Leffler J, Arenas E, Ernfors P, Marklund U, Linnarsson S (2018) Molecular Architecture of the Mouse Nervous System. Cell 174 (4):999-1014 e1022. doi:10.1016/j.cell.2018.06.021

75. Vavougios GD (2020) Host proteases as determinants of coronaviral neurotropism and virulence. Brain Behav Immun 87:27. doi:10.1016/j.bbi.2020.04.010

76. Vavougios GD (2020) The continuum of SARS-CoV-2's neurotropism and the potential for immune-mediated neuronal injury. Seizure 80:48. doi:10.1016/j.seizure.2020.05.014

77. Millet JK, Whittaker GR (2015) Host cell proteases: Critical determinants of coronavirus tropism and pathogenesis. Virus Res 202:120-134. doi:10.1016/j.virusres.2014.11.021

78. Oppo V, Melis M, Melis M, Tomassini Barbarossa I, Cossu G (2020) "Smelling and Tasting" Parkinson's Disease: Using Senses to Improve the Knowledge of the Disease. Front Aging Neurosci 12:43. doi:10.3389/fnagi.2020.00043

79. Haehner A, Hummel T, Reichmann H (2011) Olfactory loss in Parkinson's disease. Parkinsons Dis 2011:450939. doi:10.4061/2011/450939

80. Radzikowska U, Ding M, Tan G, Zhakparov D, Peng Y, Wawrzyniak P, Wang M, Li S, Morita H, Altunbulakli C, Reiger M, Neumann AU, Lunjani N, Traidl-Hoffmann C, Nadeau K, O'Mahony L, Akdis CA, Sokolowska M (2020) Distribution of ACE2, CD147, CD26 and other SARSCoV-2 associated molecules in tissues and immune cells in health and in asthma, COPD, obesity, hypertension, and COVID-19 risk factors. Allergy. doi:10.1111/all.14429

81. Fantini J, Di Scala C, Chahinian H, Yahi N (2020) Structural and molecular modelling studies reveal a new mechanism of action of chloroquine and hydroxychloroquine against SARS-CoV2 infection. Int J Antimicrob Agents 55 (5):105960. doi:10.1016/j.ijantimicag.2020.105960

82. Tortorici MA, Walls AC, Lang Y, Wang C, Li Z, Koerhuis D, Boons GJ, Bosch BJ, Rey FA, de Groot RJ, Veesler D (2019) Structural basis for human coronavirus attachment to sialic acid receptors. Nat Struct Mol Biol 26 (6):481-489. doi:10.1038/s41594-019-0233-y

83. Lu Y, Liu DX, Tam JP (2008) Lipid rafts are involved in SARS-CoV entry into Vero E6 cells. Biochem Biophys Res Commun 369 (2):344-349. doi:10.1016/j.bbrc.2008.02.023

84. Hassanzadeh K, Perez Pena H, Dragotto J, Buccarello L, Iorio F, Pieraccini S, Sancini G, Feligioni M (2020) Considerations around the SARS-CoV-2 Spike Protein with Particular Attention to COVID-19 Brain Infection and Neurological Symptoms. ACS Chem Neurosci. doi:10.1021/acschemneuro.0c00373

85. Patanavanich R, Glantz SA (2020) Smoking is Associated with COVID-19 Progression: A MetaAnalysis. Nicotine Tob Res. doi:10.1093/ntr/ntaa082

86. Guo FR (2020) Smoking links to the severity of COVID-19: An update of a meta-analysis. J Med Virol. doi:10.1002/jmv.25967

87. Zhao Q, Meng M, Kumar R, Wu Y, Huang J, Lian N, Deng Y, Lin S (2020) The impact of COPD and smoking history on the severity of COVID-19: A systemic review and meta-analysis. J Med Virol. doi:10.1002/jmv.25889 
88. Smith JC, Sheltzer JM (2020) Cigarette smoke triggers the expansion of a subpopulation of respiratory epithelial cells that express the SARS-CoV-2 receptor ACE2. bioRxiv. doi:10.1101/2020.03.28.013672

89. Cai G, Bosse Y, Xiao F, Kheradmand F, Amos CI (2020) Tobacco Smoking Increases the Lung Gene Expression of ACE2, the Receptor of SARS-CoV-2. Am J Respir Crit Care Med 201 (12):1557-1559. doi:10.1164/rccm.202003-0693LE

90. Leung JM, Yang CX, Tam A, Shaipanich T, Hackett TL, Singhera GK, Dorscheid DR, Sin DD (2020) ACE-2 expression in the small airway epithelia of smokers and COPD patients: implications for COVID-19. Eur Respir J 55 (5). doi:10.1183/13993003.00688-2020

91. Russo P, Bonassi S, Giacconi R, Malavolta M, Tomino C, Maggi F (2020) COVID-19 and smoking: is nicotine the hidden link? Eur Respir J 55 (6). doi:10.1183/13993003.01116-2020

92. Leung JM, Yang CX, Sin DD (2020) COVID-19 and nicotine as a mediator of ACE-2. Eur Respir J 55 (6). doi:10.1183/13993003.01261-2020

93. Smith JC, Sausville EL, Girish V, Yuan ML, Vasudevan A, John KM, Sheltzer JM (2020) Cigarette Smoke Exposure and Inflammatory Signaling Increase the Expression of the SARSCoV-2 Receptor ACE2 in the Respiratory Tract. Dev Cell 53 (5):514-529 e513. doi:10.1016/j.devcel.2020.05.012

94. Qing E, Hantak MP, Galpalli GG, Gallagher T (2020) Evaluating MERS-CoV Entry Pathways. Methods Mol Biol 2099:9-20. doi:10.1007/978-1-0716-0211-9_2

95. Stopsack KH, Mucci LA, Antonarakis ES, Nelson PS, Kantoff PW (2020) TMPRSS2 and COVID-19: Serendipity or Opportunity for Intervention? Cancer Discov 10 (6):779-782. doi:10.1158/2159-8290.CD-20-0451

96. Chakladar J, Shende N, Li WT, Rajasekaran M, Chang EY, Ongkeko WM (2020) SmokingMediated Upregulation of the Androgen Pathway Leads to Increased SARS-CoV-2 Susceptibility. Int J Mol Sci 21 (10). doi:10.3390/ijms21103627

97. Choi JY, Lee HK, Park JH, Cho SJ, Kwon M, Jo C, Koh YH (2020) Altered COVID-19 receptor ACE2 expression in a higher risk group for cerebrovascular disease and ischemic stroke. Biochem Biophys Res Commun 528 (3):413-419. doi:10.1016/j.bbrc.2020.05.203

98. Palasca O, Santos A, Stolte C, Gorodkin J, Jensen LJ (2018) TISSUES 2.0: an integrative web resource on mammalian tissue expression. Database (Oxford) 2018. doi:10.1093/database/bay028

99. Bender SJ, Phillips JM, Scott EP, Weiss SR (2010) Murine coronavirus receptors are differentially expressed in the central nervous system and play virus strain-dependent roles in neuronal spread. J Virol 84 (21):11030-11044. doi:10.1128/JVI.02688-09

100. Weiss SR, Leibowitz JL (2011) Coronavirus pathogenesis. Adv Virus Res 81:85-164. doi:10.1016/B978-0-12-385885-6.00009-2

101. Weiss SR (2020) Forty years with coronaviruses. J Exp Med 217 (5). doi:10.1084/jem.20200537

102. Paniz-Mondolfi A, Bryce C, Grimes Z, Gordon RE, Reidy J, Lednicky J, Sordillo EM, Fowkes M (2020) Central nervous system involvement by severe acute respiratory syndrome coronavirus-2 (SARS-CoV-2). J Med Virol 92 (7):699-702. doi:10.1002/jmv.25915

103. Baig AM (2016) Primary Amoebic Meningoencephalitis: Neurochemotaxis and Neurotropic Preferences of Naegleria fowleri. ACS Chem Neurosci 7 (8):1026-1029. doi:10.1021/acschemneuro.6b00197

104. Baig AM (2017) Emerging Insights for Better Delivery of Chemicals and Stem Cells to the Brain. ACS Chem Neurosci 8 (6):1119-1121. doi:10.1021/acschemneuro.7b00106

105. Wang W, Xu Y, Gao R, Lu R, Han K, Wu G, Tan W (2020) Detection of SARS-CoV-2 in Different Types of Clinical Specimens. JAMA. doi:10.1001/jama.2020.3786 
106. Zou L, Ruan F, Huang M, Liang L, Huang H, Hong Z, Yu J, Kang M, Song Y, Xia J, Guo Q, Song T, He J, Yen HL, Peiris M, Wu J (2020) SARS-CoV-2 Viral Load in Upper Respiratory Specimens of Infected Patients. N Engl J Med 382 (12):1177-1179. doi:10.1056/NEJMc2001737

107. Lechien JR, Chiesa-Estomba CM, De Siati DR, Horoi M, Le Bon SD, Rodriguez A, Dequanter D, Blecic S, El Afia F, Distinguin L, Chekkoury-Idrissi Y, Hans S, Delgado IL, CalvoHenriquez C, Lavigne P, Falanga C, Barillari MR, Cammaroto G, Khalife M, Leich P, Souchay C, Rossi C, Journe F, Hsieh J, Edjlali M, Carlier R, Ris L, Lovato A, De Filippis C, Coppee F, Fakhry N, Ayad T, Saussez S (2020) Olfactory and gustatory dysfunctions as a clinical presentation of mild-to-moderate forms of the coronavirus disease (COVID-19): a multicenter European study. Eur Arch Otorhinolaryngol 277 (8):2251-2261. doi:10.1007/s00405-02005965-1

108. Chen M, Shen W, Rowan NR, Kulaga H, Hillel A, Ramanathan M, Jr., Lane AP (2020) Elevated ACE2 expression in the olfactory neuroepithelium: implications for anosmia and upper respiratory SARS-CoV-2 entry and replication. bioRxiv. doi:10.1101/2020.05.08.084996

109. Menter T, Haslbauer JD, Nienhold R, Savic S, Deigendesch H, Frank S, Turek D, Willi N, Pargger H, Bassetti S, Leuppi JD, Cathomas G, Tolnay M, Mertz KD, Tzankov A (2020) Postmortem examination of COVID-19 patients reveals diffuse alveolar damage with severe capillary congestion and variegated findings in lungs and other organs suggesting vascular dysfunction. Histopathology. doi:10.1111/his.14134

110. Torabi A, Mohammadbagheri E, Akbari Dilmaghani N, Bayat AH, Fathi M, Vakili K, Alizadeh R, Rezaeimirghaed O, Hajiesmaeili M, Ramezani M, Simani L, Aliaghaei A (2020) Proinflammatory Cytokines in the Olfactory Mucosa Result in COVID-19 Induced Anosmia. ACS Chem Neurosci 11 (13):1909-1913. doi:10.1021/acschemneuro.0c00249

111. Schlosser RJ, Mulligan JK, Hyer JM, Karnezis TT, Gudis DA, Soler ZM (2016) Mucous Cytokine Levels in Chronic Rhinosinusitis-Associated Olfactory Loss. JAMA Otolaryngol Head Neck Surg 142 (8):731-737. doi:10.1001/jamaoto.2016.0927

112. Abdul Razzak R, Florence GJ, Gunn-Moore FJ (2019) Approaches to CNS Drug Delivery with a Focus on Transporter-Mediated Transcytosis. Int J Mol Sci 20 (12). doi:10.3390/ijms20123108

113. Doran KS, Banerjee A, Disson O, Lecuit M (2013) Concepts and mechanisms: crossing host barriers. Cold Spring Harb Perspect Med 3 (7). doi:10.1101/cshperspect.a010090

114. Delaney C, Campbell M (2017) The blood brain barrier: Insights from development and ageing. Tissue Barriers 5 (4):e1373897. doi:10.1080/21688370.2017.1373897

115. Saint-Pol J, Gosselet F, Duban-Deweer S, Pottiez G, Karamanos Y (2020) Targeting and Crossing the Blood-Brain Barrier with Extracellular Vesicles. Cells 9 (4). doi:10.3390/cells9040851

116. Leda AR, Bertrand L, Andras IE, El-Hage N, Nair M, Toborek M (2019) Selective Disruption of the Blood-Brain Barrier by Zika Virus. Front Microbiol 10:2158. doi:10.3389/fmicb.2019.02158

117. Mustafa YM, Meuren LM, Coelho SVA, de Arruda LB (2019) Pathways Exploited by Flaviviruses to Counteract the Blood-Brain Barrier and Invade the Central Nervous System. Front Microbiol 10:525. doi:10.3389/fmicb.2019.00525

118. Chaves AJ, Vergara-Alert J, Busquets N, Valle R, Rivas R, Ramis A, Darji A, Majo N (2014) Neuroinvasion of the highly pathogenic influenza virus H7N1 is caused by disruption of the blood brain barrier in an avian model. PLoS One 9 (12):e115138. doi:10.1371/journal.pone.0115138

119. Chai Q, He WQ, Zhou M, Lu H, Fu ZF (2014) Enhancement of blood-brain barrier permeability and reduction of tight junction protein expression are modulated by chemokines/cytokines induced by rabies virus infection. J Virol 88 (9):4698-4710. doi:10.1128/JVI.03149-13 
120. Wang L, Cao Y, Tang Q, Liang G (2013) Role of the blood-brain barrier in rabies virus infection and protection. Protein Cell 4 (12):901-903. doi:10.1007/s13238-013-3918-8

121. Paterson R (2005) How West Nile virus crosses the blood-brain barrier. Lancet Neurol 4 (1):18. doi:10.1016/s1474-4422(04)00957-3

122. Diamond MS, Klein RS (2004) West Nile virus: crossing the blood-brain barrier. Nat Med 10 (12):1294-1295. doi:10.1038/nm1204-1294

123. Berger JR, Avison M (2004) The blood brain barrier in HIV infection. Front Biosci 9:2680-2685. doi: $10.2741 / 1427$

124. Marshall DW (1988) HIV penetration of the BBB. Neurology 38 (6):1000-1001. doi:10.1212/wnl.38.6.1000-b

125. Resnick L, Berger JR, Shapshak P, Tourtellotte WW (1988) Early penetration of the blood-brainbarrier by HIV. Neurology 38 (1):9-14. doi:10.1212/wnl.38.1.9

126. Dahm T, Rudolph H, Schwerk C, Schroten H, Tenenbaum T (2016) Neuroinvasion and Inflammation in Viral Central Nervous System Infections. Mediators Inflamm 2016:8562805. doi: $10.1155 / 2016 / 8562805$

127. Al-Obaidi MMJ, Bahadoran A, Wang SM, Manikam R, Raju CS, Sekaran SD (2018) Disruption of the blood brain barrier is vital property of neurotropic viral infection of the central nervous system. Acta Virol 62 (1):16-27. doi:10.4149/av_2018_102

128. Daniels BP, Holman DW, Cruz-Orengo L, Jujjavarapu H, Durrant DM, Klein RS (2014) Viral pathogen-associated molecular patterns regulate blood-brain barrier integrity via competing innate cytokine signals. mBio 5 (5):e01476-01414. doi:10.1128/mBio.01476-14

129. Spindler KR, Hsu TH (2012) Viral disruption of the blood-brain barrier. Trends Microbiol 20 (6):282-290. doi:10.1016/j.tim.2012.03.009

130. Setiadi A, Korim WS, Elsaafien K, Yao ST (2018) The role of the blood-brain barrier in hypertension. Exp Physiol 103 (3):337-342. doi:10.1113/EP086434

131. Zaki N, Alashwal H, Ibrahim S (2020) Association of hypertension, diabetes, stroke, cancer, kidney disease, and high-cholesterol with COVID-19 disease severity and fatality: A systematic review. Diabetes Metab Syndr 14 (5):1133-1142. doi:10.1016/j.dsx.2020.07.005

132. Parveen R, Sehar N, Bajpai R, Bharal Agarwal N (2020) Association of diabetes and hypertension with disease severity in covid-19 patients: a systematic literature review and exploratory meta-analysis. Diabetes Res Clin Pract:108295. doi:10.1016/j.diabres.2020.108295

133. Espinosa OA, Zanetti ADS, Antunes EF, Longhi FG, Matos TA, Battaglini PF (2020) Prevalence of comorbidities in patients and mortality cases affected by SARS-CoV2: a systematic review and meta-analysis. Rev Inst Med Trop Sao Paulo 62:e43. doi:10.1590/S1678-9946202062043

134. Gold MS, Sehayek D, Gabrielli S, Zhang X, McCusker C, Ben-Shoshan M (2020) COVID-19 and comorbidities: a systematic review and meta-analysis. Postgrad Med:1-7. doi:10.1080/00325481.2020.1786964

135. Surma S, Romanczyk M, Labuzek K (2020) Coronavirus SARS-Cov-2 and arterial hypertension - facts and myths. Pol Merkur Lekarski 48 (285):195-198

136. Abbott NJ (2002) Astrocyte-endothelial interactions and blood-brain barrier permeability. J Anat 200 (6):629-638. doi:10.1046/j.1469-7580.2002.00064.x

137. Pedersen SF, Ho YC (2020) SARS-CoV-2: a storm is raging. J Clin Invest 130 (5):2202-2205. doi:10.1172/JCI137647

138. Chen G, Wu D, Guo W, Cao Y, Huang D, Wang H, Wang T, Zhang X, Chen H, Yu H, Zhang X, Zhang M, Wu S, Song J, Chen T, Han M, Li S, Luo X, Zhao J, Ning Q (2020) Clinical and 
immunological features of severe and moderate coronavirus disease 2019. J Clin Invest 130 (5):2620-2629. doi:10.1172/JCI137244

139. Tan M, Liu Y, Zhou R, Deng X, Li F, Liang K, Shi Y (2020) Immunopathological characteristics of coronavirus disease 2019 cases in Guangzhou, China. Immunology 160 (3):261-268. doi:10.1111/imm.13223

140. Yang AP, Li HM, Tao WQ, Yang XJ, Wang M, Yang WJ, Liu JP (2020) Infection with SARSCoV-2 causes abnormal laboratory results of multiple organs in patients. Aging (Albany NY) 12 (11):10059-10069. doi:10.18632/aging. 103255

141. Yang Y, Shen C, Li J, Yuan J, Wei J, Huang F, Wang F, Li G, Li Y, Xing L, Peng L, Yang M, Cao M, Zheng H, Wu W, Zou R, Li D, Xu Z, Wang H, Zhang M, Zhang Z, Gao GF, Jiang C, Liu L, Liu Y (2020) Plasma IP-10 and MCP-3 levels are highly associated with disease severity and predict the progression of COVID-19. J Allergy Clin Immunol 146 (1):119-127 e114. doi:10.1016/j.jaci.2020.04.027

142. Chen X, Zhao B, Qu Y, Chen Y, Xiong J, Feng Y, Men D, Huang Q, Liu Y, Yang B, Ding J, Li F (2020) Detectable serum SARS-CoV-2 viral load (RNAaemia) is closely correlated with drastically elevated interleukin 6 (IL-6) level in critically ill COVID-19 patients. Clin Infect Dis. doi:10.1093/cid/ciaa449

143. Qin C, Zhou L, Hu Z, Zhang S, Yang S, Tao Y, Xie C, Ma K, Shang K, Wang W, Tian DS (2020) Dysregulation of immune response in patients with COVID-19 in Wuhan, China. Clin Infect Dis. doi:10.1093/cid/ciaa248

144. Zhang C, Wu Z, Li JW, Zhao H, Wang GQ (2020) Cytokine release syndrome in severe COVID19: interleukin-6 receptor antagonist tocilizumab may be the key to reduce mortality. Int $\mathbf{J}$ Antimicrob Agents 55 (5):105954. doi:10.1016/j.jjantimicag.2020.105954

145. Takahashi E, Indalao IL, Sawabuchi T, Mizuno K, Sakai S, Kimoto T, Kim H, Kido H (2018) Clarithromycin suppresses induction of monocyte chemoattractant protein-1 and matrix metalloproteinase-9 and improves pathological changes in the lungs and heart of mice infected with influenza A virus. Comp Immunol Microbiol Infect Dis 56:6-13. doi:10.1016/j.cimid.2017.11.002

146. Muhammad S, Planz O, Schwaninger M (2016) Increased Plasma Matrix Metalloproteinase-9 Levels Contribute to Intracerebral Hemorrhage during Thrombolysis after Concomitant Stroke and Influenza Infection. Cerebrovasc Dis Extra 6 (2):50-59. doi:10.1159/000447750

147. Muhammad S, Haasbach E, Kotchourko M, Strigli A, Krenz A, Ridder DA, Vogel AB, Marti $\mathrm{HH}, \mathrm{Al}$-Abed Y, Planz O, Schwaninger M (2011) Influenza virus infection aggravates stroke outcome. Stroke 42 (3):783-791. doi:10.1161/STROKEAHA.110.596783

148. Hackenberg KAM, Rajabzadeh-Oghaz H, Dreier R, Buchholz BA, Navid A, Rocke DM, Abdulazim A, Hanggi D, Siddiqui A, Macdonald RL, Meng H, Etminan N (2020) Collagen Turnover in Relation to Risk Factors and Hemodynamics in Human Intracranial Aneurysms. Stroke 51 (5):1624-1628. doi:10.1161/STROKEAHA.120.029335

149. Bongetta D, Calloni T, Colombo EV, Versace A, Assietti R (2020) Do matrix metalloproteases mediate the SARS-CoV-2-related damage to the central nervous system? Brain Behav Immun. doi:10.1016/j.bbi.2020.05.050

150. Wu Y, Xu X, Chen Z, Duan J, Hashimoto K, Yang L, Liu C, Yang C (2020) Nervous system involvement after infection with COVID-19 and other coronaviruses. Brain Behav Immun 87:18-22. doi:10.1016/j.bbi.2020.03.031

151. Buzhdygan TP, DeOre BJ, Baldwin-Leclair A, McGary H, Razmpour R, Galie PA, Potula R, Andrews AM, Ramirez SH (2020) The SARS-CoV-2 spike protein alters barrier function in 2D static and 3D microfluidic in vitro models of the human blood-brain barrier. bioRxiv. doi:10.1101/2020.06.15.150912 
152. Swanson PA, McGavern D (2015) Portals of Viral Entry into the Central Nervous System. In: Dorovini-Zis K (ed) The Blood Brain Barrier in Health and Disease, vol Volume 2: Pathophysiology and Pathology. CRC Press. doi:10.1201/b19299-3

153. Ackermann M, Verleden SE, Kuehnel M, Haverich A, Welte T, Laenger F, Vanstapel A, Werlein C, Stark H, Tzankov A, Li WW, Li VW, Mentzer SJ, Jonigk D (2020) Pulmonary Vascular Endothelialitis, Thrombosis, and Angiogenesis in Covid-19. N Engl J Med 383 (2):120-128. doi:10.1056/NEJMoa2015432

154. Channappanavar R, Perlman S (2017) Pathogenic human coronavirus infections: causes and consequences of cytokine storm and immunopathology. Semin Immunopathol 39 (5):529-539. doi:10.1007/s00281-017-0629-x

155. Bulfamante G, Chiumello D, Canevini MP, Priori A, Mazzanti M, Centanni S, Felisati G (2020) First ultrastructural autoptic findings of SARS -Cov-2 in olfactory pathways and brainstem. Minerva Anestesiol 86 (6):678-679. doi:10.23736/S0375-9393.20.14772-2

156. Huang YH, Jiang D, Huang JT (2020) SARS-CoV-2 Detected in Cerebrospinal Fluid by PCR in a Case of COVID-19 Encephalitis. Brain Behav Immun 87:149. doi:10.1016/j.bbi.2020.05.012

157. Duong L, Xu P, Liu A (2020) Meningoencephalitis without respiratory failure in a young female patient with COVID-19 infection in Downtown Los Angeles, early April 2020. Brain Behav Immun 87:33. doi:10.1016/j.bbi.2020.04.024

158. Domingues RB, Mendes-Correa MC, de Moura Leite FBV, Sabino EC, Salarini DZ, Claro I, Santos DW, de Jesus JG, Ferreira NE, Romano CM, Soares CAS (2020) First case of SARSCOV-2 sequencing in cerebrospinal fluid of a patient with suspected demyelinating disease. $\mathrm{J}$ Neurol. doi:10.1007/s00415-020-09996-w

159. Moriguchi T, Harii N, Goto J, Harada D, Sugawara H, Takamino J, Ueno M, Sakata H, Kondo K, Myose N, Nakao A, Takeda M, Haro H, Inoue O, Suzuki-Inoue K, Kubokawa K, Ogihara S, Sasaki T, Kinouchi H, Kojin H, Ito M, Onishi H, Shimizu T, Sasaki Y, Enomoto N, Ishihara H, Furuya S, Yamamoto T, Shimada S (2020) A first case of meningitis/encephalitis associated with SARS-Coronavirus-2. Int J Infect Dis 94:55-58. doi:10.1016/j.ijid.2020.03.062

160. Zubair AS, McAlpine LS, Gardin T, Farhadian S, Kuruvilla DE, Spudich S (2020) Neuropathogenesis and Neurologic Manifestations of the Coronaviruses in the Age of Coronavirus Disease 2019: A Review. JAMA Neurol. doi:10.1001/jamaneurol.2020.2065

161. Hocke AC, Becher A, Knepper J, Peter A, Holland G, Tonnies M, Bauer TT, Schneider P, Neudecker J, Muth D, Wendtner CM, Ruckert JC, Drosten C, Gruber AD, Laue M, Suttorp N, Hippenstiel S, Wolff T (2013) Emerging human middle East respiratory syndrome coronavirus causes widespread infection and alveolar damage in human lungs. Am J Respir Crit Care Med 188 (7):882-886. doi:10.1164/rccm.201305-0954LE

162. Zhou L, Zhang M, Wang J, Gao J (2020) Sars-Cov-2: Underestimated damage to nervous system. Travel Med Infect Dis:101642. doi:10.1016/j.tmaid.2020.101642

163. Ubogu EE (2020) Biology of the human blood-nerve barrier in health and disease. Exp Neurol 328:113272. doi:10.1016/j.expneurol.2020.113272

164. Reinhold AK, Rittner HL (2020) Characteristics of the nerve barrier and the blood dorsal root ganglion barrier in health and disease. Exp Neurol 327:113244. doi:10.1016/j.expneurol.2020.113244

165. Palladino SP, Helton ES, Jain P, Dong C, Crowley MR, Crossman DK, Ubogu EE (2017) The Human Blood-Nerve Barrier Transcriptome. Sci Rep 7 (1):17477. doi:10.1038/s41598-01717475-y

166. Li YC, Bai WZ, Hirano N, Hayashida T, Taniguchi T, Sugita Y, Tohyama K, Hashikawa T (2013) Neurotropic virus tracing suggests a membranous-coating-mediated mechanism for transsynaptic communication. J Comp Neurol 521 (1):203-212. doi:10.1002/cne.23171 
167. Matsuda K, Park CH, Sunden Y, Kimura T, Ochiai K, Kida H, Umemura T (2004) The vagus nerve is one route of transneural invasion for intranasally inoculated influenza a virus in mice. Vet Pathol 41 (2):101-107. doi:10.1354/vp.41-2-101

168. Ubogu EE (2013) Chemokine-dependent signaling pathways in the peripheral nervous system. Methods Mol Biol 1013:17-30. doi:10.1007/978-1-62703-426-5_2

169. Cardona AE, Ubogu EE (eds) (2013) Chemokines: Methods and Protocols, vol 1013. Methods in Molecular Biology. doi:10.1007/978-1-62703-426-5_2

170. van Doorn PA, Ruts L, Jacobs BC (2008) Clinical features, pathogenesis, and treatment of Guillain-Barre syndrome. Lancet Neurol 7 (10):939-950. doi:10.1016/S1474-4422(08)70215-1

171. Agosti E, Giorgianni A, D'Amore F, Vinacci G, Balbi S, Locatelli D (2020) Is Guillain-Barre syndrome triggered by SARS-CoV-2? Case report and literature review. Neurol Sci. doi:10.1007/s10072-020-04553-9

172. Zhou Z, Kang H, Li S, Zhao X (2020) Understanding the neurotropic characteristics of SARSCoV-2: from neurological manifestations of COVID-19 to potential neurotropic mechanisms. $\mathbf{J}$ Neurol 267 (8):2179-2184. doi:10.1007/s00415-020-09929-7

173. Yin XX, Zheng XR, Peng W, Wu ML, Mao XY (2020) Vascular Endothelial Growth Factor (VEGF) as a Vital Target for Brain Inflammation during the COVID-19 Outbreak. ACS Chem Neurosci 11 (12):1704-1705. doi:10.1021/acschemneuro.0c00294

174. Lim TK, Shi XQ, Martin HC, Huang H, Luheshi G, Rivest S, Zhang J (2014) Blood-nerve barrier dysfunction contributes to the generation of neuropathic pain and allows targeting of injured nerves for pain relief. Pain 155 (5):954-967. doi:10.1016/j.pain.2014.01.026

175. Dalakas MC (2020) Guillain-Barre syndrome: The first documented COVID-19-triggered autoimmune neurologic disease: More to come with myositis in the offing. Neurol Neuroimmunol Neuroinflamm 7 (5). doi:10.1212/NXI.0000000000000781

176. Ellul MA, Benjamin L, Singh B, Lant S, Michael BD, Easton A, Kneen R, Defres S, Sejvar J, Solomon T (2020) Neurological associations of COVID-19. Lancet Neurol. doi:10.1016/S14744422(20)30221-0

177. Bostanciklioglu M (2020) SARS-CoV2 entry and spread in the lymphatic drainage system of the brain. Brain Behav Immun 87:122-123. doi:10.1016/j.bbi.2020.04.080

178. Benveniste H, Liu X, Koundal S, Sanggaard S, Lee H, Wardlaw J (2019) The Glymphatic System and Waste Clearance with Brain Aging: A Review. Gerontology 65 (2):106-119. doi:10.1159/000490349

179. Da Mesquita S, Fu Z, Kipnis J (2018) The Meningeal Lymphatic System: A New Player in Neurophysiology. Neuron 100 (2):375-388. doi:10.1016/j.neuron.2018.09.022

180. Aspelund A, Antila S, Proulx ST, Karlsen TV, Karaman S, Detmar M, Wiig H, Alitalo K (2015) A dural lymphatic vascular system that drains brain interstitial fluid and macromolecules. J Exp Med 212 (7):991-999. doi:10.1084/jem.20142290

181. Varga Z, Flammer AJ, Steiger P, Haberecker M, Andermatt R, Zinkernagel AS, Mehra MR, Schuepbach RA, Ruschitzka F, Moch H (2020) Endothelial cell infection and endotheliitis in COVID-19. Lancet 395 (10234):1417-1418. doi:10.1016/S0140-6736(20)30937-5

182. Esposito G, Pesce M, Seguella L, Sanseverino W, Lu J, Sarnelli G (2020) Can the enteric nervous system be an alternative entrance door in SARS-CoV2 neuroinvasion? Brain Behav Immun 87:93-94. doi:10.1016/j.bbi.2020.04.060

183. Jin X, Lian JS, Hu JH, Gao J, Zheng L, Zhang YM, Hao SR, Jia HY, Cai H, Zhang XL, Yu GD, Xu KJ, Wang XY, Gu JQ, Zhang SY, Ye CY, Jin CL, Lu YF, Yu X, Yu XP, Huang JR, Xu KL, Ni Q, Yu CB, Zhu B, Li YT, Liu J, Zhao H, Zhang X, Yu L, Guo YZ, Su JW, Tao JJ, Lang GJ, Wu XX, Wu WR, Qv TT, Xiang DR, Yi P, Shi D, Chen Y, Ren Y, Qiu YQ, Li LJ, Sheng J, 
Yang Y (2020) Epidemiological, clinical and virological characteristics of 74 cases of coronavirus-infected disease 2019 (COVID-19) with gastrointestinal symptoms. Gut 69 (6):1002-1009. doi:10.1136/gutjnl-2020-320926

184. Zhou J, Li C, Zhao G, Chu H, Wang D, Yan HH, Poon VK, Wen L, Wong BH, Zhao X, Chiu MC, Yang D, Wang Y, Au-Yeung RKH, Chan IH, Sun S, Chan JF, To KK, Memish ZA, Corman VM, Drosten C, Hung IF, Zhou Y, Leung SY, Yuen KY (2017) Human intestinal tract serves as an alternative infection route for Middle East respiratory syndrome coronavirus. Sci Adv 3 (11):eaao4966. doi:10.1126/sciadv.aao4966

185. Lee HW, Chung YS, Kim TJ (2020) Heterogeneity of Human gammadelta T Cells and Their Role in Cancer Immunity. Immune Netw 20 (1):e5. doi:10.4110/in.2020.20.e5

186. Krzysztof NJ, Christoffer LJ, Rahul K, Ricanek P, Jonas H, Jack S (2020) Age, inflammation and disease location are critical determinants of intestinal expression of SARS-CoV-2 receptor ACE2 and TMPRSS2 in inflammatory bowel disease. Gastroenterology. doi:10.1053/j.gastro.2020.05.030

187. Lamers MM, Beumer J, van der Vaart J, Knoops K, Puschhof J, Breugem TI, Ravelli RBG, Paul van Schayck J, Mykytyn AZ, Duimel HQ, van Donselaar E, Riesebosch S, Kuijpers HJH, Schipper D, van de Wetering WJ, de Graaf M, Koopmans M, Cuppen E, Peters PJ, Haagmans BL, Clevers H (2020) SARS-CoV-2 productively infects human gut enterocytes. Science 369 (6499):50-54. doi:10.1126/science.abc1669

188. Monteil V, Kwon H, Prado P, Hagelkruys A, Wimmer RA, Stahl M, Leopoldi A, Garreta E, Hurtado Del Pozo C, Prosper F, Romero JP, Wirnsberger G, Zhang H, Slutsky AS, Conder R, Montserrat N, Mirazimi A, Penninger JM (2020) Inhibition of SARS-CoV-2 Infections in Engineered Human Tissues Using Clinical-Grade Soluble Human ACE2. Cell 181 (4):905-913 e907. doi:10.1016/j.cell.2020.04.004

189. Colmenero I, Santonja C, Alonso-Riano M, Noguera-Morel L, Hernandez-Martin A, Andina D, Wiesner T, Rodriguez-Peralto JL, Requena L, Torrelo A (2020) SARS-CoV-2 endothelial infection causes COVID-19 chilblains: histopathological, immunohistochemical and ultraestructural study of 7 paediatric cases. Br J Dermatol. doi:10.1111/bjd.19327

190. Wang Y, Liu S, Liu H, Li W, Lin F, Jiang L, Li X, Xu P, Zhang L, Zhao L, Cao Y, Kang J, Yang J, Li L, Liu X, Li Y, Nie R, Mu J, Lu F, Zhao S, Lu J, Zhao J (2020) SARS-CoV-2 infection of the liver directly contributes to hepatic impairment in patients with COVID-19. J Hepatol. doi:10.1016/j.jhep.2020.05.002

191. Pesaresi M, Pirani F, Tagliabracci A, Valsecchi M, Procopio AD, Busardo FP, Graciotti L (2020) SARS-CoV-2 identification in lungs, heart and kidney specimens by transmission and scanning electron microscopy. Eur Rev Med Pharmacol Sci 24 (9):5186-5188. doi:10.26355/eurrev_202005_21217

192. Soung A, Klein RS (2018) Viral Encephalitis and Neurologic Diseases: Focus on Astrocytes. Trends Mol Med 24 (11):950-962. doi:10.1016/j.molmed.2018.09.001

193. Abassi Z, Knaney Y, Karram T, Heyman SN (2020) The Lung Macrophage in SARS-CoV-2 Infection: A Friend or a Foe? Front Immunol 11:1312. doi:10.3389/fimmu.2020.01312

194. Yang D, Chu H, Hou Y, Chai Y, Shuai H, Lee AC, Zhang X, Wang Y, Hu B, Huang X, Yuen TT, Cai JP, Zhou J, Yuan S, Zhang AJ, Chan JF, Yuen KY (2020) Attenuated interferon and pro-inflammatory response in SARS-CoV-2-infected human dendritic cells is associated with viral antagonism of STAT1 phosphorylation. J Infect Dis. doi:10.1093/infdis/jiaa356

195. Shieh WJ, Hsiao CH, Paddock CD, Guarner J, Goldsmith CS, Tatti K, Packard M, Mueller L, Wu MZ, Rollin P, Su IJ, Zaki SR (2005) Immunohistochemical, in situ hybridization, and ultrastructural localization of SARS-associated coronavirus in lung of a fatal case of severe acute respiratory syndrome in Taiwan. Hum Pathol 36 (3):303-309.

doi:10.1016/j.humpath.2004.11.006 
196. Chen Y, Feng Z, Diao B, Wang R, Wang G, Wang C, Tan Y, Liu L, Wang C, Liu Y, Liu Y, Yuan Z, Ren L, Wu Y (2020) The Novel Severe Acute Respiratory Syndrome Coronavirus 2 (SARS-CoV-2) Directly Decimates Human Spleens and Lymph Nodes. medRxiv:2020.2003.2027.20045427. doi:10.1101/2020.03.27.20045427

197. Gu J, Gong E, Zhang B, Zheng J, Gao Z, Zhong Y, Zou W, Zhan J, Wang S, Xie Z, Zhuang H, Wu B, Zhong H, Shao H, Fang W, Gao D, Pei F, Li X, He Z, Xu D, Shi X, Anderson VM, Leong AS (2005) Multiple organ infection and the pathogenesis of SARS. J Exp Med 202 (3):415-424. doi:10.1084/jem.20050828

198. Jaunmuktane Z, Mahadeva U, Green A, Sekhawat V, Barrett NA, Childs L, Shankar-Hari M, Thom M, Jager HR, Brandner S (2020) Microvascular injury and hypoxic damage: emerging neuropathological signatures in COVID-19. Acta Neuropathol. doi:10.1007/s00401-020-021902

199. Badierah RA, Uversky VN, Redwan EM (2020) Dancing with Trojan horses: an interplay between the extracellular vesicles and viruses. J Biomol Struct Dyn:1-27. doi:10.1080/07391102.2020.1756409

200. Elrashdy F, Aljaddawi AA, Redwan EM, Uversky VN (2020) On the potential role of exosomes in the COVID-19 reinfection/reactivation opportunity. J Biomol Struct Dyn:1-12. doi:10.1080/07391102.2020.1790426

201. Ogando NS, Dalebout TJ, Zevenhoven-Dobbe JC, Limpens R, van der Meer Y, Caly L, Druce J, de Vries JJC, Kikkert M, Barcena M, Sidorov I, Snijder EJ (2020) SARS-coronavirus-2 replication in Vero E6 cells: replication kinetics, rapid adaptation and cytopathology. J Gen Virol. doi:10.1099/jgv.0.001453

202. Velandia-Romero ML, Calderon-Pelaez MA, Balbas-Tepedino A, Marquez-Ortiz RA, Madronero LJ, Barreto Prieto A, Castellanos JE (2020) Extracellular vesicles of U937 macrophage cell line infected with DENV-2 induce activation in endothelial cells EA.hy926. PLoS One 15 (1):e0227030. doi:10.1371/journal.pone.0227030

203. Basso M, Bonetto V (2016) Extracellular Vesicles and a Novel Form of Communication in the Brain. Front Neurosci 10:127. doi:10.3389/fnins.2016.00127

204. Yanez-Mo M, Siljander PR, Andreu Z, Zavec AB, Borras FE, Buzas EI, Buzas K, Casal E, Cappello F, Carvalho J, Colas E, Cordeiro-da Silva A, Fais S, Falcon-Perez JM, Ghobrial IM, Giebel B, Gimona M, Graner M, Gursel I, Gursel M, Heegaard NH, Hendrix A, Kierulf P, Kokubun K, Kosanovic M, Kralj-Iglic V, Kramer-Albers EM, Laitinen S, Lasser C, Lener T, Ligeti E, Line A, Lipps G, Llorente A, Lotvall J, Mancek-Keber M, Marcilla A, Mittelbrunn M, Nazarenko I, Nolte-'t Hoen EN, Nyman TA, O'Driscoll L, Olivan M, Oliveira C, Pallinger E, Del Portillo HA, Reventos J, Rigau M, Rohde E, Sammar M, Sanchez-Madrid F, Santarem N, Schallmoser K, Ostenfeld MS, Stoorvogel W, Stukelj R, Van der Grein SG, Vasconcelos MH, Wauben MH, De Wever O (2015) Biological properties of extracellular vesicles and their physiological functions. J Extracell Vesicles 4:27066. doi:10.3402/jev.v4.27066

205. Nordman JC, Phillips WS, Kodama N, Clark SG, Del Negro CA, Kabbani N (2014) Axon targeting of the alpha 7 nicotinic receptor in developing hippocampal neurons by Gprin 1 regulates growth. J Neurochem 129 (4):649-662. doi:10.1111/jnc.12641

206. Nordman JC, Muldoon P, Clark S, Damaj MI, Kabbani N (2014) The alpha4 nicotinic receptor promotes CD4+ T-cell proliferation and a helper T-cell immune response. Mol Pharmacol 85 (1):50-61. doi:10.1124/mol.113.088484

207. Tolu S, Eddine R, Marti F, David V, Graupner M, Pons S, Baudonnat M, Husson M, Besson M, Reperant C, Zemdegs J, Pages C, Hay YA, Lambolez B, Caboche J, Gutkin B, Gardier AM, Changeux JP, Faure P, Maskos U (2013) Co-activation of VTA DA and GABA neurons mediates nicotine reinforcement. Mol Psychiatry 18 (3):382-393. doi:10.1038/mp.2012.83 
208. Changeux JP (2010) Nicotine addiction and nicotinic receptors: lessons from genetically modified mice. Nat Rev Neurosci 11 (6):389-401. doi:10.1038/nrn2849

209. Kabbani N, Olds JL (2020) Does COVID19 Infect the Brain? If So, Smokers Might Be at a Higher Risk. Mol Pharmacol 97 (5):351-353. doi:10.1124/molpharm.120.000014

210. Ferrari MF, Raizada MK, Fior-Chadi DR (2007) Nicotine modulates the renin-angiotensin system of cultured neurons and glial cells from cardiovascular brain areas of Wistar Kyoto and spontaneously hypertensive rats. J Mol Neurosci 33 (3):284-293. doi:10.1007/s12031-0079006-x

211. Ferrari MF, Raizada MK, Fior-Chadi DR (2008) Differential regulation of the renin-angiotensin system by nicotine in WKY and SHR glia. J Mol Neurosci 35 (2):151-160. doi:10.1007/s12031007-9025-7

212. Oakes JM, Fuchs RM, Gardner JD, Lazartigues E, Yue X (2018) Nicotine and the reninangiotensin system. Am J Physiol Regul Integr Comp Physiol 315 (5):R895-R906. doi:10.1152/ajpregu.00099.2018

213. Olds JL, Kabbani N (2020) Is nicotine exposure linked to cardiopulmonary vulnerability to COVID-19 in the general population? FEBS J. doi:10.1111/febs.15303

214. Zhang QL, Ding YQ, Hou JL, He L, Huang ZX, Wang HJ, Cai JJ, Zhang JH, Zhang WL, Geng J, Li X, Kang W, Yang L, Shen H, Li ZG, Han HX, Lu YD (2003) [Detection of severe acute respiratory syndrome (SARS)-associated coronavirus RNA in autopsy tissues with in situ hybridization]. Di Yi Jun Yi Da Xue Xue Bao 23 (11):1125-1127

215. Chong PY, Chui P, Ling AE, Franks TJ, Tai DY, Leo YS, Kaw GJ, Wansaicheong G, Chan KP, Ean Oon LL, Teo ES, Tan KB, Nakajima N, Sata T, Travis WD (2004) Analysis of deaths during the severe acute respiratory syndrome (SARS) epidemic in Singapore: challenges in determining a SARS diagnosis. Arch Pathol Lab Med 128 (2):195-204. doi:10.1043/15432165(2004)128<195:AODDTS >2.0.CO;2

216. Inoue Y, Tanaka N, Tanaka Y, Inoue S, Morita K, Zhuang M, Hattori T, Sugamura K (2007) Clathrin-dependent entry of severe acute respiratory syndrome coronavirus into target cells expressing ACE2 with the cytoplasmic tail deleted. J Virol 81 (16):8722-8729. doi:10.1128/JVI.00253-07

217. Kaparianos A, Argyropoulou E (2011) Local renin-angiotensin II systems, angiotensinconverting enzyme and its homologue ACE2: their potential role in the pathogenesis of chronic obstructive pulmonary diseases, pulmonary hypertension and acute respiratory distress syndrome. Curr Med Chem 18 (23):3506-3515. doi:10.2174/092986711796642562

218. Ye Q, Wang B, Mao J (2020) The pathogenesis and treatment of the 'Cytokine Storm' in COVID-19. J Infect 80 (6):607-613. doi:10.1016/j.jinf.2020.03.037

219. Serrano-Castro PJ, Estivill-Torrus G, Cabezudo-Garcia P, Reyes-Bueno JA, Ciano Petersen N, Aguilar-Castillo MJ, Suarez-Perez J, Jimenez-Hernandez MD, Moya-Molina MA, OliverMartos B, Arrabal-Gomez C, Rodriguez de Fonseca F (2020) Impact of SARS-CoV-2 infection on neurodegenerative and neuropsychiatric diseases: a delayed pandemic? Neurologia 35 (4):245-251. doi:10.1016/j.nrl.2020.04.002

220. Boe DM, Boule LA, Kovacs EJ (2017) Innate immune responses in the ageing lung. Clin Exp Immunol 187 (1):16-25. doi:10.1111/cei.12881

221. Koyuncu OO, Hogue IB, Enquist LW (2013) Virus infections in the nervous system. Cell Host Microbe 13 (4):379-393. doi:10.1016/j.chom.2013.03.010

222. Huang J, Zheng M, Tang X, Chen Y, Tong A, Zhou L (2020) Potential of SARS-CoV-2 to Cause CNS Infection: Biologic Fundamental and Clinical Experience. Front Neurol 11:659. doi:10.3389/fneur.2020.00659 
223. McGavern DB, Kang SS (2011) Illuminating viral infections in the nervous system. Nat Rev Immunol 11 (5):318-329. doi:10.1038/nri2971

224. Kaul M, Garden GA, Lipton SA (2001) Pathways to neuronal injury and apoptosis in HIVassociated dementia. Nature 410 (6831):988-994. doi:10.1038/35073667

225. Ayala-Nunez NV, Follain G, Delalande F, Hirschler A, Partiot E, Hale GL, Bollweg BC, Roels J, Chazal M, Bakoa F, Carocci M, Bourdoulous S, Faklaris O, Zaki SR, Eckly A, Uring-Lambert B, Doussau F, Cianferani S, Carapito C, Jacobs FMJ, Jouvenet N, Goetz JG, Gaudin R (2019) Zika virus enhances monocyte adhesion and transmigration favoring viral dissemination to neural cells. Nat Commun 10 (1):4430. doi:10.1038/s41467-019-12408-x

226. Desforges M, Miletti TC, Gagnon M, Talbot PJ (2007) Activation of human monocytes after infection by human coronavirus 229E. Virus Res 130 (1-2):228-240. doi:10.1016/j.virusres.2007.06.016

227. Collins AR (2002) In vitro detection of apoptosis in monocytes/macrophages infected with human coronavirus. Clin Diagn Lab Immunol 9 (6):1392-1395. doi:10.1128/cdli.9.6.13921395.2002

228. Patterson S, Macnaughton MR (1982) Replication of human respiratory coronavirus strain 229E in human macrophages. J Gen Virol 60 (Pt 2):307-314. doi:10.1099/0022-1317-60-2-307

229. Xu J, Zhong S, Liu J, Li L, Li Y, Wu X, Li Z, Deng P, Zhang J, Zhong N, Ding Y, Jiang Y (2005) Detection of severe acute respiratory syndrome coronavirus in the brain: potential role of the chemokine mig in pathogenesis. Clin Infect Dis 41 (8):1089-1096. doi:10.1086/444461

230. Tay MZ, Poh CM, Renia L, MacAry PA, Ng LFP (2020) The trinity of COVID-19: immunity, inflammation and intervention. Nat Rev Immunol 20 (6):363-374. doi:10.1038/s41577-0200311-8

231. Huang C, Wang Y, Li X, Ren L, Zhao J, Hu Y, Zhang L, Fan G, Xu J, Gu X, Cheng Z, Yu T, Xia J, Wei Y, Wu W, Xie X, Yin W, Li H, Liu M, Xiao Y, Gao H, Guo L, Xie J, Wang G, Jiang R, Gao Z, Jin Q, Wang J, Cao B (2020) Clinical features of patients infected with 2019 novel coronavirus in Wuhan, China. Lancet 395 (10223):497-506. doi:10.1016/S01406736(20)30183-5

232. Xu P, Zhou Q, Xu J (2020) Mechanism of thrombocytopenia in COVID-19 patients. Ann Hematol 99 (6):1205-1208. doi:10.1007/s00277-020-04019-0

233. Nwafor DC, Brichacek AL, Mohammad AS, Griffith J, Lucke-Wold BP, Benkovic SA, Geldenhuys WJ, Lockman PR, Brown CM (2019) Targeting the Blood-Brain Barrier to Prevent Sepsis-Associated Cognitive Impairment. J Cent Nerv Syst Dis 11:1179573519840652. doi:10.1177/1179573519840652

234. Wang L, Shen Y, Li M, Chuang H, Ye Y, Zhao H, Wang H (2020) Clinical manifestations and evidence of neurological involvement in 2019 novel coronavirus SARS-CoV-2: a systematic review and meta-analysis. J Neurol. doi:10.1007/s00415-020-09974-2

235. Matthay MA, Zemans RL (2011) The acute respiratory distress syndrome: pathogenesis and treatment. Annu Rev Pathol 6:147-163. doi:10.1146/annurev-pathol-011110-130158

236. Noris M, Benigni A, Remuzzi G (2020) The case of complement activation in COVID-19 multiorgan impact. Kidney Int 98 (2):314-322. doi:10.1016/j.kint.2020.05.013

237. Wadman M, Couzin-Frankel J, Kaiser J, Matacic C (2020) A rampage through the body. Science 368 (6489):356-360. doi:10.1126/science.368.6489.356

238. Gralinski LE, Sheahan TP, Morrison TE, Menachery VD, Jensen K, Leist SR, Whitmore A, Heise MT, Baric RS (2018) Complement Activation Contributes to Severe Acute Respiratory Syndrome Coronavirus Pathogenesis. mBio 9 (5). doi:10.1128/mBio.01753-18 
239. Risitano AM, Mastellos DC, Huber-Lang M, Yancopoulou D, Garlanda C, Ciceri F, Lambris JD (2020) Complement as a target in COVID-19? Nat Rev Immunol 20 (6):343-344. doi:10.1038/s41577-020-0320-7

240. Jacob A, Alexander JJ (2014) Complement and blood-brain barrier integrity. Mol Immunol 61 (2):149-152. doi:10.1016/j.molimm.2014.06.039

241. Franceschi C, Bonafe M, Valensin S, Olivieri F, De Luca M, Ottaviani E, De Benedictis G (2000) Inflamm-aging. An evolutionary perspective on immunosenescence. Ann N Y Acad Sci 908:244-254. doi:10.1111/j.1749-6632.2000.tb06651.x

242. Meftahi GH, Jangravi Z, Sahraei H, Bahari Z (2020) The possible pathophysiology mechanism of cytokine storm in elderly adults with COVID-19 infection: the contribution of "inflameaging". Inflamm Res. doi:10.1007/s00011-020-01372-8

243. Armutcu F (2019) Organ crosstalk: the potent roles of inflammation and fibrotic changes in the course of organ interactions. Inflamm Res 68 (10):825-839. doi:10.1007/s00011-019-01271-7

244. Lu R, Kiernan MC, Murray A, Rosner MH, Ronco C (2015) Kidney-brain crosstalk in the acute and chronic setting. Nat Rev Nephrol 11 (12):707-719. doi:10.1038/nrneph.2015.131

245. Siddiqi HK, Mehra MR (2020) COVID-19 illness in native and immunosuppressed states: A clinical-therapeutic staging proposal. J Heart Lung Transplant 39 (5):405-407. doi:10.1016/j.healun.2020.03.012

246. Akhmerov A, Marban E (2020) COVID-19 and the Heart. Circ Res 126 (10):1443-1455. doi:10.1161/CIRCRESAHA.120.317055

247. Li H, Liu L, Zhang D, Xu J, Dai H, Tang N, Su X, Cao B (2020) SARS-CoV-2 and viral sepsis: observations and hypotheses. Lancet 395 (10235):1517-1520. doi:10.1016/S01406736(20)30920-X 


\section{Figure legends}

Figure 1: Respiratory and extra respiratory organ/system COVID-19 prevalence.

Figure 2: Diagram for human blood-nervous-system-barriers. A. Blood-Cerebrospinal Fluid (BCSFB)/ choroid plexus barrier (1. Fenestrated endothelium, 2. Interstitial matrix, 3 and 4. Choroid plexus epithelium, 5. Brain cells). B. Blood-Cerebrospinal Fluid (BCSFB)/Meningeal barrier (1. arachnoid, 2. Trabeculae cross section, 3. Pericyte, 4. Epithelial cell tight junction, 5. Epithelial cell, 6. CSF, 7. Pia Mater). C. Blood-Brain Barrier (1. Astrocyte, 2. Basement membrane, 3. Pericyte, 4. Endothelial cell [non- fenestrated], 5. Tight junction). D1. Blood Nerve barrier BNB (cross section) (1. Epineurium, 2. Perineurium, 3. Endoneurial vessel, 4. Basal lamina. 5. Endoneurium, 6. Myelin, 7. Nucleus of Schwann cell, 8. Axon, 9. Endoneurial endothelial cells of microvessel, 10. Epineurium blood vessel). D2. Blood-nerve Barrier. E. Blood olfactory nerve barrier. F. Inside the glomeruli barriers both of glomerular endothelial and epithelial cells (known as podocytes) crosstalk occurs, where they share the glomerular basement membrane. G. inside the glomerular both of peritubular capillary endothelial and tubular epithelial cells crosstalk also occurs through the barrier where they are separated by a tubular basement membrane and interstitial space. Both of kidney epithelial (podocytes and tubular) are breached with SARS-CoV-2 in COVID-19 patients (reviewed in [200]). From her the viral and/or its components can spread from renal anastomosis into CNS via nerve supply. Although the crosstalk between human organs in health and diseases is a very complicated processes go through huge number of mechanisms, but it well documented in a dramatically pattern [243,244].

Figure 3: Classification of COVID-19 disease stages. The figure illustrates three escalating phases of COVID-19 disease progression, with hypothesis of blood-endothelial/epithelial barriers integrity/permeability scale associated with age and comorbidities diseases over the three stages. The blood-endothelial barriers are representative for all body barriers and specifically for blood-Nervous system Barrier (BNSB). Progressive increase in inflammatory cytokine and chemokines eventually leads to cytokine storm in a profile similar to in sepsis cases, which eventually leads to endothelial-barriers dysfunction. Many other biomarkers molecules (in addition to the cytokine storm elements) have a direct effect on the BNSB as discussed in text. The times on the $\mathrm{X}$-axis are approximate. The figure designed based on and adapted from [200,245,246,114,113,247]. + to >4+ indicative for barrier integrity/permeability like scale, IIA (stage II without hypoxia) IIB (Stage II with hypoxia). Tumor Necrosis Factor (TNF- $\alpha$ ), Interleukin $1 \beta$ (IL-1 $\beta$ ), IL-6, GCSF: granulocyte-colony stimulating factor, interferon gamma-induced protein-10, monocyte chemoattractant protein-1, and MCA-protein 1: macrophage inflammatory proteins $1-\alpha$. 
Table 1: Ultrastructure features of SARS-CoV-2 viral particles in human nervous tissues and endothelial system

\begin{tabular}{|c|c|c|c|c|}
\hline Ref. & Sample type & Sample source & $\begin{array}{l}\text { Viral particle } \\
\text { size }\end{array}$ & Virus features \\
\hline$[102]$ & post-mortem & $\begin{array}{ll}\text { frontal lobe } \\
\text { tissue }\end{array}$ & $80-110 \mathrm{~nm}$ & $\begin{array}{l}\text { two morphologically distinct types of spike } \\
\text { protein structures, typical of betacoronaviruses, } \\
\text { viral particles in frontal lobe brain sections, } \\
\text { Individual and in small vesicles of endothelial } \\
\text { cells of a Pleomorphic spherical viral-like } \\
\text { particles were observed, Blebbing of viral-like } \\
\text { particles coming in/out of the endothelial wall } \\
\text { which pointing to presumed active pathogen } \\
\text { entry-transit (transcellular penetration) across the } \\
\text { brain microvascular endothelial cells into the } \\
\text { neural niche was recorded, Neural cell bodies } \\
\text { exhibited distended cytoplasmic vacuoles } \\
\text { containing enveloped viral particle exhibiting } \\
\text { electron dense centers with distinct stalk-like } \\
\text { peplomeric projections }\end{array}$ \\
\hline$[155]$ & $\begin{array}{l}\text { Autopsy within } \\
\text { three hours post- } \\
\text { mortem }\end{array}$ & $\begin{array}{l}\text { Human } \\
\text {.Olfactory } \\
\text { nerve, } \\
\text {. Gyrus, } \\
\text {. Brainstem }\end{array}$ & $98-160 \mathrm{~nm}$ & $\begin{array}{l}\text { Spherical particle with crown-like shape and } \\
\text { inner dense core and electron-dense periphery, } \\
\text { double nuclear envelope, severe damage in the } \\
\text { olfactory nerve, autophagy phenomena appeared } \\
\text { in the cytoplasm }\end{array}$ \\
\hline [229] & $\begin{array}{l}\text { post-mortem } \\
\text { autopsy }\end{array}$ & $\begin{array}{lr}\text { Autopsy } & \text { brain } \\
\text { tissue } & \text { was } \\
\text { cultured } & \text { with } \\
\text { Vero E6 for } \\
\text { E.M. }\end{array}$ & $\sim 80-90 \mathrm{~nm}$ & $\begin{array}{l}\text { Clear cytopathic effect, enveloped virus particles } \\
\text { with morphology compatible with coronavirus., } \\
\text { Extracellular particles were found clustering and } \\
\text { adhering to the surface of the plasma Membrane, } \\
\text { the Immunostaining demonstrated that monokine } \\
\text { induced by interferon- } \gamma \text { (Mig) expressed in } \\
\text { gliocytes with the infiltration of CD68+ } \\
\text { monocytes/macrophages and CD3+ T } \\
\text { lymphocytes } \\
\text { in the brain mesenchyme }\end{array}$ \\
\hline [181] & $\begin{array}{l}\text { post-mortem } \\
\text { autopsy }\end{array}$ & $\begin{array}{l}\text { Human } \\
\text { transplanted } \\
\text { kidney }\end{array}$ & $150 \mathrm{~nm}$ & $\begin{array}{l}\text { Viral inclusion bodies in peipenilubular space } \\
\text { and viral particles in endothelial cells, aggregates } \\
\text { of viral particles with dense circular surface and } \\
\text { lucid centre, capillaries containing viral particles. }\end{array}$ \\
\hline [189] & skin biopsies & $\begin{array}{l}\text { Human } \\
\text { chilblains }\end{array}$ & $92.26 \mathrm{~nm}$ & $\begin{array}{l}\text { Immunohistochemistry and transmission } \\
\text { electron microscopy presented the viral particles } \\
\text { within endothelial cells in lesion skin biopsies } \\
\text { from patients presenting with chilblains. } \\
\text { Ultrastructural examination revealed the } \\
\text { presence of round membrane-bound structures } \\
\text { within the cytoplasm of endothelial cells } \\
\text { showing an electro-lucent centre, and surrounded } \\
\text { by tiny spikes, giving them a halo-like } \\
\text { appearance. Their mean diameter was } 92.26 \mathrm{~nm} \\
(80.76-109.76 \mathrm{~nm}) \text {, and the mean thickness of the } \\
\text { spikes was } 13.18 \mathrm{~nm}(12.36-13.88 \mathrm{~nm})\end{array}$ \\
\hline [153] & $\begin{array}{l}\text { Pulmonary } \\
\text { autopsy }\end{array}$ & $\begin{array}{l}\text { Human } \\
\text { pulmonary }\end{array}$ & - & $\begin{array}{l}\text { SARS-CoV-2 particles within the destructed } \\
\text { lung vascular endothelial cell, which expressed } \\
\text { 8.3-fold more ACE2 than non COVID-19 } \\
\text { samples. A total of } 79 \text { inflammation-related } \\
\text { genes were differentially regulated only in } \\
\text { specimens from patients with Covid-19. }\end{array}$ \\
\hline
\end{tabular}




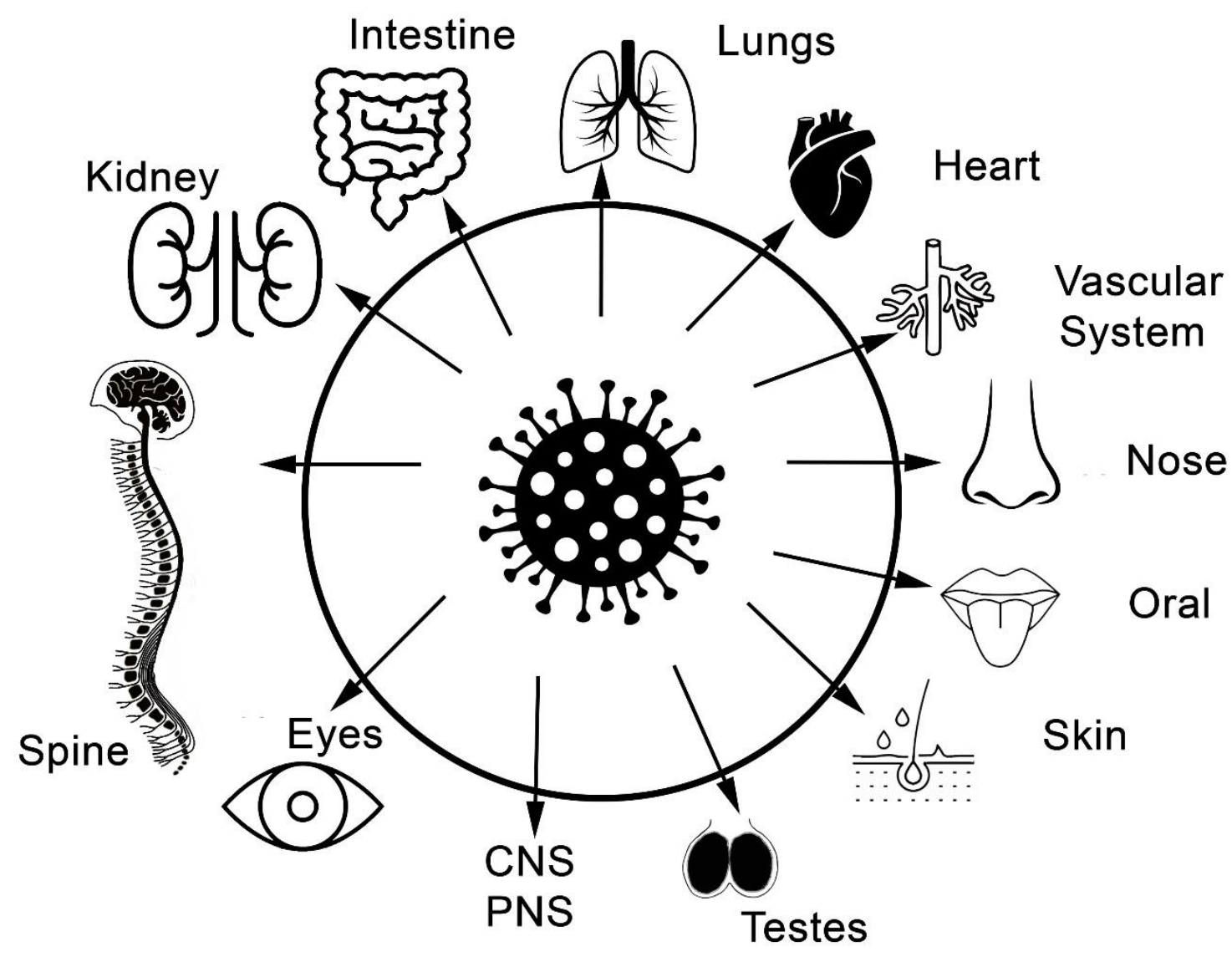

Figure 1 

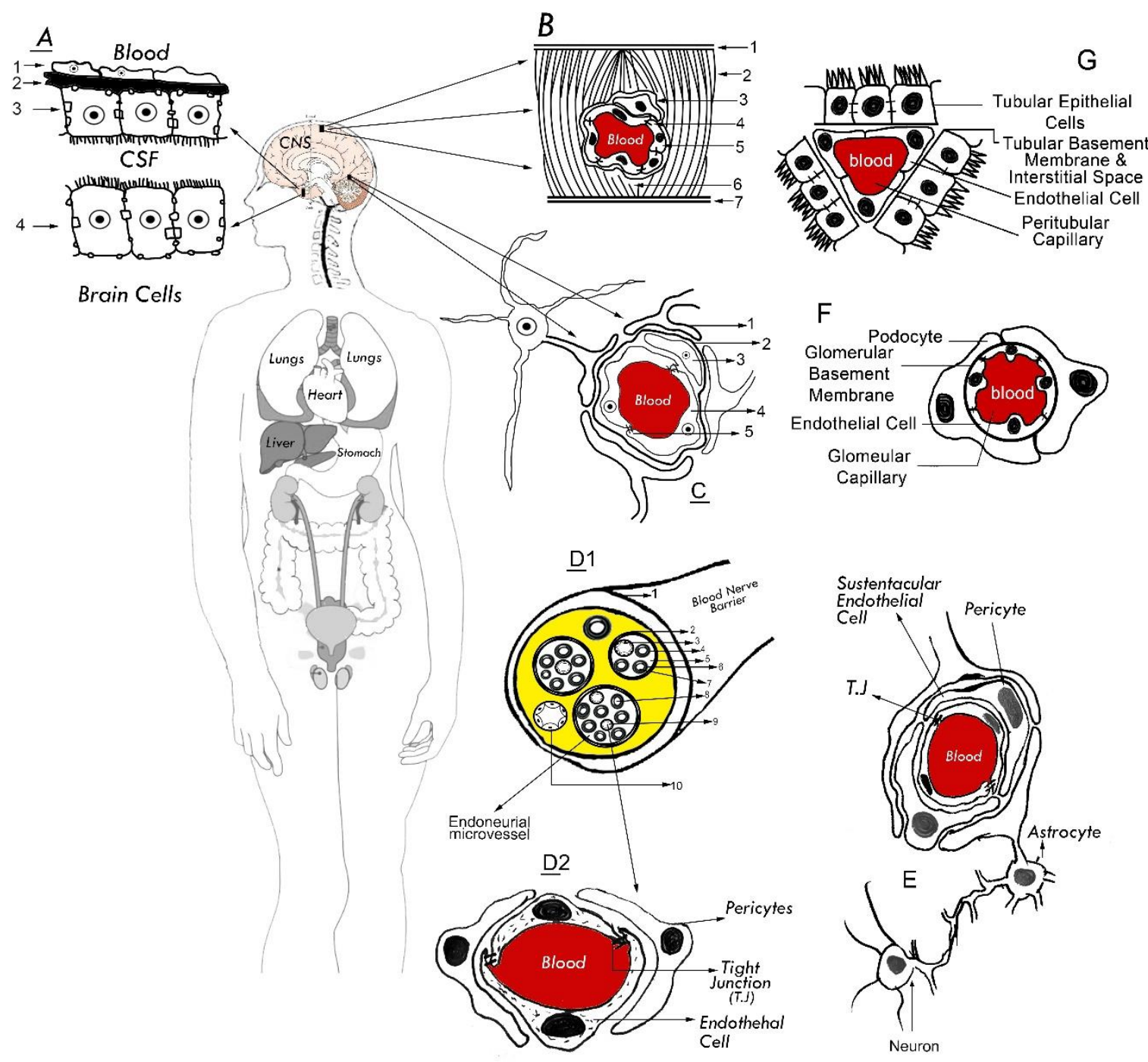

Figure 2 




Figure 3 